\title{
LA INFLUENCIA DE LOS TEXTOS NO VINCULANTES DEL CONSEJO DE EUROPA SOBRE INDEPENDENCIA JUDICIAL EN EL TEDH Y EN LA UE
}

\author{
RAFAEL BUSTOS GISBERT \\ Catedrático de Derecho Constitucional \\ Universidad Complutense de Madrid
}

TRC, n. ${ }^{\circ} 47,2021$, pp. 161-198

ISSN 1139-5583

\section{SUMARIO}

I. Introducción. II. Primera fase (1990-2010): la construcción de las bases del concepto de independencia judicial en el CoE. III. Segunda fase (2010-2020): la lucha por la independencia judicial. IV. Recapitulación: los estándares europeos sobre independencia judicial. V. La creciente eficacia (indirecta) de los estándares en materia de independencia.

\section{INTRODUCCIÓN}

Pese a que la defensa del Estado de Derecho sea una de las tres finalidades básicas del Consejo de Europa (CoE, en adelante), lo cierto es que la actividad concreta de los órganos del Consejo en esta materia se vio desde el principio lastrada por los inevitables elementos de intergubernamentalidad de la propia organización. En este punto ha de diferenciarse de la protección de los derechos que, tras la lenta puesta en marcha del TEDH y, hasta 1998, de la Comisión, adquirió una estabilidad y productividad creciente mediante un control externo realizado por vías jurisdiccionales vinculantes. Por contra, la protección del Estado de Derecho tuvo que esperar a los años noventa y adoptó la forma de normas no vinculantes.

De este modo la definición por el Consejo de Europa de la independencia judicial como principio estructurador del Estado de Derecho en una democracia pluralista se ha construido por sus órganos políticos y consultivos mediante la adopción de textos y de documentos de muy diferente naturaleza. Englobamos todos estos 
textos bajo el rótulo genérico de soft Law, entendido en su sentido más amplio. Esto es, en la aproximación de López Guerra, no solo como acuerdos multilaterales, sino también como declaraciones o recomendaciones de los órganos ejecutivos o deliberantes de órganos internacionales o incluso de órganos asesores o de supervisión de dichas organizaciones ${ }^{1}$. Estos textos tendrían en común que no son jurídicamente vinculantes, si bien ello no significa que carezcan totalmente de efectos jurídicos ${ }^{2}$. Y ello porque, especialmente en el ámbito del $\mathrm{CoE}$, hasta cierto punto expresan el consenso común en una materia entre los Estados miembros de la organización. Con ello adquieren un valor hermenéutico y heurístico relevante sobre todo en cuanto garantizan la consideración de, por ejemplo, el CEDH como un instrumento vivo y a menudo acaba conformando el contenido de los estándares jurídicos exigibles mediante su incorporación a decisiones vinculantes. Este proceso resulta particularmente claro cuando el TEDH los incorpora en sus decisiones ${ }^{4}$.

En la creación y desarrollo de este acervo jurídico conviene apuntar desde el comienzo la enorme importancia que en este contexto adquirieron lo que Claes y De Visser denominan comunidades judiciales transnacionales. Foros de intercambio y deliberación de los jueces europeos. En el caso del CoE se tratará en su mayoría de comunidades institucionalizadas dentro del $\mathrm{CoE}$, pero algunos documentos procederán de otro tipo de sedes de discusión ${ }^{5}$.

El examen de la materia ha de comenzar con sus primeras formulaciones en los años noventa donde se sentarán las bases del concepto de independencia judicial y un desarrollo del mismo a partir de 2010. Las fechas, como veremos, no son casuales.

\section{PRIMERA FASE (1990-2010): LA CONSTRUCCIÓN DE LAS BASES DEL CONCEPTO DE INDEPENDENCIA JUDICIAL EN EL COE}

En la lenta puesta en marcha de la definición de la independencia judicial conviene destacar cuatro hitos fundamentales: la Recomendación del Consejo de

1 López Guerra, L., «Soft Law y sus efectos en el ámbito del Derecho europeo de los Derechos Humanos», Teoría y Derecho, n. ${ }^{\circ} 11,2012$, p. 151.

2 Así A. Peters, apunta cómo este tipo de normas se escapa al análisis binario habitual para definir lo que es o no es derecho a partir de su vigencia o no. La autora centra su análisis en el soft Law de la UE pero es igualmente aplicable al CoE, «Soft law as a new mode of governance, Diedrichs, U. et al, The Dynamics of Change in EU Governance, Elgar Publisher, 2011, pp. 22 a 25.

3 López Guerra, ibidem, pp. 160 a 163.

4 Sobre el tema de nuevo el esclarecedor análisis de López GuERrA, ibidem, pp. 154 a 160. Veremos más adelante como el TEDH usará esta vía cuando tenga que incrementar las garantías de la independencia judicial a partir de 2013 .

$5 \mathrm{El}$ análisis se centra en las redes vinculadas a la UE, pero es perfectamente aplicable al CoE, CLAES, M. \& De Visser, M., «Are you Networked Yet?, On Dialogues in European Judicial Networks», Utrecht Law Review, vol 8, n. ${ }^{\circ}$ 2, 2010, p. 100. Nos hemos ocupado de estas formas de relación entre jueces recientemente, Bustos Gisbert, R., «Comunicación transjudicial en Europa en defensa de la independencia de los jueces», RDCE, n. ${ }^{\circ} 33,2020$. 
ministros 94(12); la Carta Europea sobre el Estatuto de los Jueces (1998); la creación y actividad de la Comisión de Venecia a partir de 1990 y la del Consejo Consultivo de los Jueces Europeos (CCJE) en 2000.

\section{La recomendación $94(12)$}

La recomendación 94(12) sobre la independencia, eficiencia y papel de los jueces adoptada por el Comité de Ministros el 13 de octubre de 1994 es el primer documento en el que el CoE realiza una aproximación global a la cuestión de la independencia judicial. Se trata de una recomendación muy breve cuyos antecedentes conectan su contenido con los Principios Básicos de Naciones Unidas en materia de independencia judicial de $1985^{6}$ y con la jurisprudencia del TEDH en relación con el artículo 6 del CEDH.

El principio Primero de la recomendación, «Principios generales sobre la independencia de los jueces», recoge los elementos básicos de la materia. Propone en concreto una serie de medidas:

a) Recomienda el reconocimiento del principio a nivel constitucional y legislativo. Especifica el concepto a partir de la intangibilidad por poderes externos de las decisiones judiciales; la garantía legal de la duración en el cargo y la remuneración de los jueces; la exclusividad de los jueces para decidir sobre el alcance de las propias competencias o la interdicción de la anulación retroactiva por la administración de las decisiones judiciales.

b) Establece la obligación de garantizar la independencia de los jueces por parte de los otros poderes del Estado.

c) Prescribe que las decisiones relativas a la carrera judicial han de basarse en méritos objetivos; en particular con referencia a la cualificación, integridad, competencia y eficiencia de los jueces e incluyendo las reglas de acceso y promoción. Considera aceptable el nombramiento de los jueces por el poder ejecutivo, aunque apunta que los procesos han de ser transparentes e independientes en la práctica de modo que las decisiones no sean influidas por factores externos. Por ello, en todo caso, han de incluir: (i) la existencia de un órgano externo e independiente que asesore de

6 Se trata de los «Principios básicos relativos a independencia de la judicatura», adoptados en el $7 .^{\circ}$ congreso de Naciones Unidas sobre prevención del delito y tratamiento del delincuente celebrado en Milán en 1985. El texto fue posteriormente confirmado en las resoluciones 40/32 y 40/146 del mismo año. En el ámbito universal son destacables también la Observación General n. ${ }^{\circ} 32$ del Comité de Derechos Humanos al art. 14 del Pacto Internacional de Derechos Civiles y Políticos, así como los Principios de Bangalore sobre conducta judicial elaborados en dicha ciudad en 2002 en el marco de los trabajos de la Oficina contra la Droga y el delito. También este contexto es relevante la labro del Relator Especial de NU sobre la independencia de magistrados y jueces creado en 1994 por la Comisión de Derechos Humanos. 
manera determinante al gobierno; (ii) el derecho de los afectados a recurrir ante una autoridad independiente y (iii) la defensa frente a las presiones externas en el caso del órgano técnico de propuesta.

d) Prohíbe cualquier forma de restricción, influencia externa o presión en el proceso de decisión judicial. Esta prohibición debe apoyarse en el establecimiento de sanciones contra todo aquel que intente presionar a los jueces. Precisa que la prohibición de toda presión abarca también a la distribución de los casos entre los jueces de modo que esta no pueda estar influida por factores externos relacionados con las partes o con los intereses de terceros en el resultado final del proceso. Igualmente considera que ha de prohibirse retirar el conocimiento de un caso a un juez excepto por razones válidas (enfermedad o conflictos de intereses). Las sanciones y los procedimientos para retirar los casos deberán estar previstos en la ley, excluir cualquier influencia gubernamental y ser adoptables solo por otro órgano judicial.

e) Determina que todo juez ha de tener garantizado el ejercicio de su cargo hasta la edad legal de jubilación o el fin del plazo para el que fueron nombrados.

A partir de tales principios generales, la recomendación desarrolla, en los principios 2 a 5 algunos aspectos más concretos como la garantía de la autoridad de los jueces (principio 2) y las condiciones adecuadas de trabajo (principio 3); el derecho a asociarse para garantizar su independencia y salvaguardar sus intereses (principio 4); y los deberes de los jueces (principio 5).

El principio 6 de la Recomendación abordará uno de los elementos claves de la independencia judicial: el cese y las sanciones a los jueces. Así, sostiene que deben adoptarse todas las medidas necesarias para garantizar la independencia judicial cuando los jueces cometen infracciones disciplinarias o no realizan adecuadamente sus funciones. Reconoce que, dependiendo de las tradiciones constitucionales de cada Estado, las medidas disciplinarias pueden incluir la retirada del conocimiento de ciertos casos, el traslado del juez, la sanción económica o la suspensión temporal. Los motivos para el cese definitivo de un juez habrán de estar previstos en la ley, pueden referirse a la incapacidad para realizar funciones judiciales, la comisión de un delito o de infracciones graves de las normas disciplinarias. La imposición de este tipo de sanciones podrá encomendarse a un órgano especial o un tribunal superior. En todo caso habrán de ser revisables judicialmente con todas las garantías propias del debido proceso.

\section{La Carta Europea sobre el Estatuto de los jueces (1998)}

Este documento comenzó a gestarse en una reunión multilateral celebrada en julio de 1997 en la que participaron representantes de 13 Estados miembros del 
CoE y diversas organizaciones y entidades vinculadas al mundo judicial europeo. El texto fue aprobado ${ }^{7}$ un año después en una segunda conferencia multilateral celebrada los días 8 a 10 de julio de 1998. Ambas conferencias fueron impulsadas por el Directorado de Asuntos Judiciales del CoE. El texto final carece de valor formal pues constituye básicamente una guía acerca de cómo debe elaborarse en los Estados miembros un Estatuto para los jueces y magistrados.

Los puntos de referencia para su redacción, según se reconoce en sus antecedentes, fueron la jurisprudencia del TEDH sobre el art. 6 CEDH, la Recomendación (94) 12 recién examinada y los ya citados principios básicos relativos a la independencia judicial de Naciones Unidas (1985). El texto se compone de cinco apartados y un memorándum explicativo.

En el primer apartado, «Principios generales», se realizan afirmaciones de diversa finalidad e importancia. Algunas son meras reiteraciones de la recomendación y otras son concreciones relativas a los Consejos Judiciales ${ }^{8}$ y al estatuto de los jueces. Sobre los Consejos Judiciales tiene en cuenta la heterogeneidad de la organización interna de los Estados. El Estatuto promueve su creación como órgano de propuesta de las decisiones sobre selección, carrera y cese de los jueces. Deberán ser independientes del resto de poderes por lo que su composición ha de incluir, al menos, un $50 \%$ de jueces elegidos por y entre sus pares. Sobre el estatuto personal de jueces y magistrados realiza afirmaciones de distinta naturaleza. Algunas puramente deontológicas; otras relativas a cuestiones institucionales y acaba destacando la relevancia de las asociaciones judiciales nacionales e internacionales para garantizar la independencia judicial.

El segundo apartado se centra en «Selección, reclutamiento y formación», pero desarrolla el tema de manera altamente insuficiente. Se limita a reiterar la importancia de que la selección será realizada por un órgano independiente. Órgano que ha de valorar únicamente méritos vinculados a la cualificación y previa experiencia en la aplicación del Derecho sin que pueda producirse ninguna discriminación.

El tercer apartado aborda el «nombramiento e inamovilidad» de jueces y magistrados. Es destacable la centralidad conferida al órgano independiente pues se entiende que el nombramiento ha de ser resultado de su propuesta, recomendación, con su acuerdo o siguiendo su opinión. El Estatuto de los jueces habrá de fijar claramente las causas que inhabilitan para desempeñar la labor de juez. En el caso de nombramientos temporales, las decisiones de cese, de renovación y de permanencia han de ser realizadas por dicho órgano independiente. Respecto a la inamovilidad, establece con claridad que cualquier nombramiento para otro puesto debe gozar del consentimiento del juez (incluso

7 La referencia del texto es DAJ DOC (98) 23.

8 Nos referiremos con este término (con independencia de su denominación en cada Estado) a los órganos específicamente creados para el autogobierno judicial, similares al Consejo General del Poder Judicial español, que en los diferentes Estados europeos adoptan distintas denominaciones y características. 
aunque sea para promocionarlo), excepto cuando sea consecuencia de sanciones disciplinarias, cambios generales en la estructura del sistema judicial o asignaciones, limitadas temporalmente, de refuerzo a otros tribunales.

El cuarto apartado regula el «desarrollo de la carrera judicial». Respecto a la promoción el Estatuto extiende la obligación del respeto al criterio del mérito, la previa fijación de los criterios objetivos, la posibilidad de recurrir judicialmente la decisión y el mantenimiento de un sistema de formación continua. En lo atinente al ejercicio de los derechos y libertades por los jueces subraya que solo pueden limitarse para garantizar la confianza ciudadana en la administración de justicia y asegurar su independencia.

El quinto apartado se centra en la «Responsabilidad» de jueces y magistrados. Tres cuestiones son objeto de examen. En primer lugar, establece las reglas básicas reguladoras del cese de un magistrado: participación del magistrado afectado; proceso respetuoso con el derecho de audiencia y de representación del juez; realizado por una autoridad independiente; principio de legalidad sancionatoria, respeto al principio de proporcionalidad entre las faltas y las sanciones; y posibilidad de recurrir las sanciones ante un tribunal. En segundo lugar, apunta que la responsabilidad por los daños causados en el ejercicio del cargo ha de estar garantizada por el Estado que solo puede repercutirla en el juez en un plazo determinado y únicamente por ruptura grave e inexcusable de las reglas de conducta judicial. En tercer lugar, aconseja que los ciudadanos puedan elevar quejas ante la autoridad judicial independiente en el caso de incumplimientos de deberes por jueces en el ejercicio de su cargo.

El sexto apartado se centra en la «Remuneración y bienestar social» de los jueces limitándose a declarar que habrán de recibir una compensación económica con un nivel suficiente para ser inmune a presiones financieras por parte de cualquiera interesado en sus decisiones. Igualmente se establece la garantía de una pensión.

Finalmente, el séptimo apartado aborda, de nuevo, el tema del «cese» de los magistrados ya examinado con la responsabilidad.

\section{Los informes de la Comisión de Venecia}

Como es conocido la Comisión de Venecia nace en el contexto histórico de la caída del muro de Berlín y ante los inminentes retos que se le iban a plantear al CoE para integrar a los Estados del otro lado del telón de acero Se crea por un acuerdo parcial de 18 Estados en 1990 y a finales de 2002 todos los Estados del CoE estaban adheridos. Actualmente la Comisión ha rebasado con creces las fronteras del CoE.

La Comisión es un órgano consultivo e independiente, constituido en el CoE y centrado en asuntos constitucionales. Su labor básica consiste en la emisión de opiniones jurídicas e informes sobre un amplio elenco de materias, aunque 
últimamente también está cobrando importancia su participación en algunos procesos como amicus curiae ${ }^{9}$. El trabajo de la Comisión que nos interesa es el relativo a reformas constitucionales y legales en marcha en los Estados miembros y el referido a la emisión de opiniones mucho más generales sobre materias que hayan sido objeto de la petición específica.

En el primer sentido, la Comisión se pronunció sobre reformas legislativas en el periodo objeto de examen (de 1990 a 2010) en más de 40 ocasiones. La heterogeneidad de los supuestos hace que no sea posible examinar uno por uno estos casos. Pero sí serán objeto de estudio cuando examinemos, vid infra, las compilaciones de opiniones publicadas en 2015 y 2019.

Interesa, sobre todo, el informe general sobre los nombramientos judiciales emitido el 22 de junio de $2007^{10}$ a petición del Consejo Consultivo de Jueces Europeos en la elaboración de su opinión n. ${ }^{\circ} 10$ sobre los Consejo Judiciales (vid infra). A pesar de su nombre, el informe versa sobre los consejos judiciales, más que sobre los nombramientos judiciales.

La opinión comienza poniendo de manifiesto la inexistencia de un único modelo de nombramiento de los jueces. Es más, la heterogeneidad entre los Estados miembros llega al punto de que modelos de nombramiento que a priori serían rechazables, como el realizado directamente por el poder ejecutivo, pueden ser aceptables y funcionan razonablemente bien en democracias consolidadas. Sin embargo, en democracias nuevas es necesaria la inclusión de mecanismos constitucionales explícitos para evitar los abusos políticos en el nombramiento de los jueces. En particular ha de excluirse un sistema de elección parlamentaria porque ello puede generar que las consideraciones políticas sean más importantes que los méritos de los candidatos en el proceso de selección. Respecto al posible nombramiento por el ejecutivo, se considera aceptable solo si está vinculado por las propuestas realizadas por un consejo judicial o similar. Este punto de partida lleva a que la Comisión claramente opte en favor de la creación de un Consejo Judicial. Este habrá de desempeñar un papel decisivo en el nombramiento, promoción y régimen disciplinario de los jueces.

La pura existencia de un Consejo Judicial no es considerada suficiente en sí misma para excluir influencias políticas en el proceso de nombramiento. La Comisión entiende necesario alcanzar un equilibrio adecuado entre la independencia y la necesaria responsabilidad del poder judicial ante la sociedad evitando

9 Sobre la Comisión véase el trabajo clásico de J. Jowell, «The Venice Commission: Disseminating Democracy through Law», Public Law, n. ${ }^{\circ}$ 24, 2001, pp. 675 y ss y el más moderno de W. HoffmanN-Riem, «The Venice Commission of the Council of Europe: Standards and Impact», International Journal of European Law , n. ${ }^{\circ}$ 25, 2014, pp. 579 y ss. En castellano véase. P. CRAIG, «Constitucionalismo transnacional: la contribución de la Comisión de Venecia», TRC, n. ${ }^{\circ} 40,2017$, pp 79 y ss y P. Biglino Campos, «La Comisión de Venecia y el Patrimonio Constitucional Común», RGDC, n. ${ }^{\circ} 28,2018$, pp. 1 y ss.

10 Comisión Venecia (European Commission for Democracy through Law). Judicial Appointments, CDL-AD(2007)028, de 22/06/2007 
un excesivo corporativismo. No hay un modelo estándar, pero ha de aceptarse que otros poderes puedan intervenir en dichos Consejos en cuanto también están interesados y han de ser capaces de ejercer algún control sobre el poder judicial. Este ha de ser responsable (answerable) ante estos, aunque ello no pueda abarcar el poder de destitución. En última instancia habrá de tenerse en cuenta que la razón de ser del Consejo es garantizar la independencia del poder judicial aislándolo de otros poderes.

Por ello resultará básico determinar su composición. La primera regla para la Comisión será que los miembros judiciales del consejo han de ser elegidos por y entre sus pares. Además, deberán constituir una parte sustancial, si no mayoritaria, del Consejo. El resto de miembros pueden ser elegidos por el parlamento pero no entre parlamentarios y a ser posible conforme a mayorías cualificadas. Admite la presencia de miembros natos del ejecutivo (singularmente el ministro de justicia) que, sin embargo, no deben participar en determinadas decisiones como la imposición de medidas disciplinarias que, de todos modos, deben poder ser recurribles ante los tribunales. El presidente debería ser elegido por el Consejo entre sus miembros no judiciales.

Respecto al nombramiento de los jueces la Comisión apenas entra en el tema. Sostiene que los dos sistemas básicos son el de oposición y el de experiencia profesional. Muestra una clara desconfianza a los nombramientos con periodo de prueba por considerarlos muy peligrosos desde el punto de vista de la independencia.

\section{Los documentos del Consejo Consultivo de los Jueces Europeos (CCJE)}

El CCJE es también un órgano consultivo creado por el Comité de Ministros del CoE en el año 2000. Su objeto es asesorar en materias relativas a la independencia, imparcialidad y competencias de los jueces. Está compuesto exclusivamente por jueces en representación de todos los Estados miembros del CoE. Igualmente tienen presencia, sin derecho a voto, otros órganos del Consejo de Europa y otras organizaciones internacionales (la UE y otros observadores).

Desde su origen su función más relevante ${ }^{11}$ es preparar opiniones sobre temas relacionados con la independencia judicial y la función jurisdiccional. Estos informes se realizarán a solicitud de sus miembros o por iniciativa de órganos del Consejo de Europa. En el periodo objeto de examen (2000 a 2010) las opiniones n. ${ }^{\circ} 1$ y 10 son particularmente importantes desde el punto de vista de la independencia judicial.

11 Véase Apéndice A: Main Actions Areas for the Purpose of Establishing Priorities within the Global Action Programme, Consultative Council of European Judges: Framework Global Action Plan for Judges in Europe. CCJE(2001)24, de 12/02/2001. 
La opinión n. ${ }^{\circ}$, de 23 de noviembre 2001, sobre las normas relativas a la independencia y a la inamovilidad de los jueces ${ }^{12}$, es el punto de partida de toda la actividad posterior. A lo largo de sus más de 70 párrafos desarrolla buena parte de los aspectos relevantes en la materia.

En su introducción destaca algunos elementos básicos de la independencia. Recuerda que la independencia es condición previa del Estado de Derecho a la vez que garantía fundamental del derecho a un juicio justo. No es un privilegio acordado en el propio interés del juez, sino en «interés de la preeminencia del Derecho y de los que buscan y reclaman justicia». La independencia ha de existir respecto a la sociedad en general, respecto a las partes y respecto al resto de poderes de quienes no se ha de estar sometido a ninguna forma de presión. Por ello, ha de asegurarse durante toda la carrera del juez desde su nombramiento y selección hasta su cese. La independencia presupone la imparcialidad respecto a las partes y al litigio del que conozcan. Esta imparcialidad no solo ha de ser percibida por las partes, sino por toda la sociedad.

Las conclusiones principales de esta opinión recogen elementos ya presentes en los documentos anteriores y desarrollan otros aspectos. Así apunta, entre otros extremos, el rango constitucional que ha de tener el principio de independencia; la limitación de la libertad de configuración del acceso y promoción la carrera judicial por la previa determinación de criterios objetivos de acceso basados en el mérito y se recomienda que el procedimiento de acceso sea reformado si se suscitan dudas sobre la posible incidencia de intereses políticos. Se insiste de nuevo en la importancia de una instancia independiente elegida mayoritariamente por los jueces y se apuntan una serie de criterios relevantes respecto al estatuto de los jueces (remuneración suficiente, inamovilidad, independencia frente a tribunales superiores y protección de datos). El informe concluye con una petición para la reforma de la Recomendación (94)12.

La segunda opinión sin duda relevante para las presentes líneas es la n. ${ }^{\circ} 10$ sobre los «Consejos de Justicia al Servicio de la Sociedad» de 23 de noviembre de 2007. El largo informe (más de 100 párrafos) continúa el trabajo realizado en la materia por los diversos órganos del CoE que desde el Estatuto de los Jueces europeos habían abordado la importancia de crear órganos independientes de defensa de la independencia judicial siguiendo el modelo de los Consejos de la Magistratura creado en Italia. El informe, por tanto, busca identificar los elementos clave de la regulación de estos consejos.

Podemos clasificar sus conclusiones y recomendaciones principales en cuatro grandes grupos. Respecto a las conclusiones generales, subraya la importancia de una instancia específica aseguradora de la independencia judicial que proteja tanto al sistema en su conjunto, como a cada juez individual. La protección tiene como objetivo último el reforzamiento de la confianza ciudadana. Para ello el Consejo

12 CCJE(2001)OPN. ${ }^{\circ} 1$. 
habrá de estar protegido frente a los poderes legislativo y ejecutivo mediante normas constitucionales.

En lo referente a la composición de los consejos, el informe se decanta por una composición mixta de jueces y legos con una mayoría sustancial de los primeros. Los criterios de designación de los miembros del consejo no deben ser de naturaleza política sino que han de vincularse a la competencia, experiencia, comprensión de la cultura judicial y en particular de la independencia. Los miembros judiciales del Consejo han de ser elegidos por los propios jueces respetando criterios de representatividad y sin la presión de los órganos políticos. Los miembros del consejo no jueces han de ser designados por autoridades no políticas. Si, a pesar de ello, lo fueran por el Parlamento han de serlo mediante mayorías cualificadas de modo que se garantice un apoyo cualificado de la oposición y con ello la debida representatividad de las diferentes sensibilidades sociales.

En lo referente a su funcionamiento, los miembros del Consejo han de trabajar con dedicación exclusiva, independencia e imparcialidad; disponer de su propio presupuesto; motivar en Derecho todas sus decisiones que, además, han de ser recurribles ante los tribunales; y operar de modo transparente y basado en la rendición de cuentas de ante la sociedad.

Finalmente, en lo atinente a sus competencias, se enumera un amplio elenco de funciones: defensa y promoción de la independencia judicial y de la eficacia de la justicia; selección, nombramiento y promoción de los jueces; evaluación del poder judicial; concreción de reglas deontológicas; y un largo etcétera.

\section{SEGUNDA FASE (2010-2020): LA LUCHA POR LA INDEPENDENCIA JUDICIAL}

El año 2010 va a ser un claro punto de inflexión respecto a la actividad de los órganos del $\mathrm{CoE}$ en materia de independencia judicial. Es difícil saber cuáles fueron los motivos del crecimiento cualitativo y cuantitativo de este conjunto de normas. Pero no parece aventurado afirmar que ello fue consecuencia, por una parte, de los resultados de los trabajos previos, en especial la ya muy consolidada Comisión de Venecia, y, por la otra y sobre todo, de la aparición de disfunciones en materia de Estado de Derecho en el Este de Europa (muy singularmente Ucrania ${ }^{13}$ ) o claramente previsibles incluso en el seno de la UE (la primera victoria electoral del partido Fisdez, liderado por V. Orban, en Hungría precisamente se produce en Abril de 2010). Sea como fuere en 2010 se aprueban tres textos esenciales para la evolución del acervo normativo del CoE

13 No deja de ser significativo, por ejemplo el Informe de la Comisión Venecia sobre la reforma judicial en Ucrania de 20/03/2007 (CDL-AD(2007)003) en el que se felicita de los avances producidos en Ucrania si se compara con el extraordinariamente crítico informe de 16/03/2010 (CDL-AD(2010)003) sobre el proyecto de ley sobre el sistema judicial y el status de los jueces en Ucrania. 
en materia de independencia judicial precisamente en el Comité de ministros, en la Comisión de Venecia y en el CCJE.

\section{Los textos de 2010}

a) Trabajos preliminares: el informe sobre independencia judicial (Parte 1) de la comisión de Venecia

En Julio de 2008 la Presidencia de la Comisión de Asuntos Jurídicos y Derechos Humanos de la Asamblea Parlamentaria del CoE solicitó a la Comisión Venecia la elaboración de un informe sobre estándares europeos relativos a la independencia del sistema judicial. Fruto de esta petición fue el Informe sobre independencia Judicial, Parte 1, aprobado en la reunión de marzo de $2010^{14}$.

La Comisión utilizó los documentos ya examinados en el apartado anterior para elaborar el informe que adoptó la misma estructura que la opinión n. ${ }^{\circ} 1$ del CCJE. Se trata de un documento que mantiene una evidente conexión con los esbozados en el apartado anterior y, por tanto, se reiteran muchos de las afirmaciones en ellos contenidos. Parte por ello de la base de que la independencia judicial tiene simultáneamente un elemento objetivo (como cualidad indispensable del poder judicial como tal) y un componente subjetivo (el derecho de todo individuo a que sus derechos sean establecidos por un juez independiente). En consecuencia, la independencia judicial no es un fin en sí mismo ni un privilegio personal de los jueces. Es una herramienta que les permite ejercer el papel de garantes de los derechos de los ciudadanos. Quizás la aportación más novedosa del documento sea la distinción entre independencia externa e interna. La primera escuda al juez frente a la influencia de otros poderes del Estado. La segunda asegura que el juez toma sus decisiones solo sobre la base de la aplicación del ordenamiento jurídico y no como consecuencia de instrucciones de jueces de más alto rango. Esta segunda ha recibido mucha menos atención, pero implica que no es aceptable una organización jerarquizada del poder judicial en el sentido de la subordinación de los jueces a los presidentes de los tribunales o a instancias judiciales superiores en el ejercicio de su concreta actividad jurisdiccional. Esto será particularmente importante en algunos países en los que la práctica de «guías» de los Tribunales Supremos o Tribunales superiores pueden implicar el riesgo de convertir a los jueces en funcionarios que aplican las decisiones de sus órganos superiores. La defensa de la independencia interna explica la inclusión en las conclusiones finales del informe de algunas garantías como la objetividad en el reparto de casos o el derecho al juez natural. 
Las conclusiones principales alcanzadas (y en algunos casos reiterativas respecto a documentos anteriores) serían agrupables en cuatro grandes grupos. Sostiene, en primer lugar, que los principios de independencia judicial han de constitucionalizarse incluyendo su separación del resto de poderes del Estado; la exclusiva sujeción de los jueces a la ley; la inexistencia de distinciones entre los propios jueces que solo se diferencian por sus diversas funciones; el derecho al juez natural y el principio de inamovilidad. Respecto al nombramiento y promoción de los jueces afirma el carácter basilar del mérito y la aplicación de criterios objetivos en el marco de la ley. En lo referente al estatuto de los jueces subraya la importancia de las normas de incompatibilidad y de recusación de los jueces; el carácter vitalicio de los nombramientos de jueces (destacando el carácter problemático de la existencia de periodos de prueba); la revisión judicial de las decisiones de los órganos disciplinarios; la remuneración suficiente; la inmunidad (solo) funcional de los jueces, la inexistencia de relaciones de subordinación con respecto a otros jueces; y el respeto al juez natural en el reparto de los asuntos. En lo relativo al gobierno judicial apoya la creación de Consejos judiciales independientes con una composición plural en la que una parte sustancial, si no mayoritaria, de sus miembros sean jueces elegidos por sus pares; una asignación presupuestaria suficiente y con participación del propio poder judicial.

\section{b) La Recomendación (2010)12}

En noviembre de 2010 el Comité de Ministros del CoE aprobó una nueva recomendación sobre Jueces: independencia, eficiencia y responsabilidades que sustituyó a la aprobada en 1994 y recogió los avances realizados por los diferentes órganos consultivos del $\mathrm{CoE}$, en especial los relativos a la importancia de la creación de los Consejos Judiciales. Respondió, según se sostiene en su memorándum explicativo, a la creciente demanda de la mayor eficiencia posible en el funcionamiento de los poderes judiciales como garantes de los derechos.

La recomendación se divide en siete capítulos y un memorándum explicativo y resulta mucho más pormenorizada que la aprobada 16 años antes.

El primer capítulo, «Aspectos Generales», recoge afirmaciones básicas claramente procedentes de los textos anteriores: el propósito de independencia judicial es el de proteger el derecho a un juicio justo; la independencia del juez individual se asegura protegiendo al Poder Judicial siendo un aspecto esencial del Estado de Derecho; los jueces han de tener una absoluta libertad para decidir los casos atribuidos; la independencia ha de garantizarse a nivel constitucional (los principios generales) y legislativo (el desarrollo de los mismos); el juez individual ha de disponer de un órgano independiente que pueda protegerle; un caso no debe ser retirado a un juez excepto por razones objetivas y predeterminadas de acuerdo con procedimientos transparentes; y solo los jueces han de definir el alcance de sus propias competencias. 
El capítulo segundo aborda la «Independencia Externa». Sostiene que han de adoptarse las medidas necesarias para promover, respetar y proteger la independencia e imparcialidad de los jueces incluso mediante la imposición de sanciones por el ejercicio de presión indebida sobre ellos. Las decisiones judiciales han de ser motivadas y públicas sin poder ser sometidas a más revisión que las previstas respecto a las apelaciones o recursos establecidos en los procedimientos judiciales y en los términos prescritos legalmente. Los poderes legislativo y ejecutivo (excepto en lo referido a amnistías e indultos) no pueden invalidar las decisiones judiciales. Ambos poderes habrán de evitar la crítica que mine la independencia o la confianza ciudadana en el poder judicial. En ningún caso deben expresar o amenazar con la intención de no aceptar una decisión de los jueces. Respecto a las presiones procedentes de la opinión pública o de los medios de comunicación, la recomendación recuerda que la actuación judicial es de interés público y por tanto la información sobre cuestiones judiciales interesa a la opinión pública. La información ha de tener en cuenta los límites dimanentes de la independencia judicial por lo que se anima a la creación en el seno del poder judicial de órganos o gabinetes de comunicación. Finalmente, en lo referido al comportamiento de los jueces, se recuerda la importancia de evitar los conflictos de interés y de que todos sus actos tengan en cuenta la necesidad de proteger su independencia e imparcialidad.

El capítulo tercero incorpora una de las principales novedades de este texto recogiendo el informe de la Comisión de Venecia recién examinado. Se centra en la «Independencia interna» entendida como la indemnidad del juez frente a presiones procedentes del propio poder judicial. Esta indemnidad implica que al decidir un caso el juez debe ser libre, sin restricciones, influencia impropia, presión, amenaza o influencia (directa o indirecta) de cualquier autoridad incluidas las del propio poder judicial. La organización jerarquizada del poder judicial no ha de limitar la independencia del juez individual. Por ello, los tribunales superiores no han de dirigir instrucciones a los jueces sobre los casos que estén conociendo, excepto en los supuestos de cuestiones prejudiciales o de apelaciones en los términos previstos legalmente. En particular, el reparto de los casos entre los jueces y tribunales ha de seguir criterios predeterminados de carácter objetivo y no estar condicionados por ningún órgano o persona que pueda tener interés en el resultado final del proceso. La independencia interna no se verá afectada por el derecho de los jueces a pertenecer a asociaciones profesionales.

El capítulo cuarto establece sus recomendaciones respecto a los «Consejos de la Judicatura» que resultan especialmente breves si las comparamos con la importancia que habían adquirido en otros documentos del CoE. Quizás la heterogeneidad en los ordenamientos jurídicos de los Estados miembros explique la existencia de una regulación de mínimos. Se limita a establecer que se trata de órganos legal o constitucionalmente establecidos para proteger la independencia del poder judicial y de los jueces individuales así como para promover un eficaz funcionamiento de la administración de justicia. Igualmente establece la conocida regla general 
respecto a que al menos la mitad de los miembros del órgano han de ser jueces elegidos entre sus pares respetando el pluralismo en el seno de la judicatura y con representación de los diferentes niveles judiciales. Los Consejos habrán de funcionar con el máximo nivel de transparencia y motivando sus decisiones. El funcionamiento del Consejo no podrá interferir en la independencia individual de los jueces.

El Capítulo quinto aborda la eficacia y recursos de los jueces de una manera comparativamente más detallada. Es destacable la mención expresa a la importancia del asociacionismo judicial no ya para la defensa de los intereses profesionales, sino también para apoyar otros principios del sistema judicial, especialmente, la independencia judicial.

El capítulo sexto desarrolla la cuestión del «Estatus del Juez» siendo uno de los más pormenorizados. Incorpora muchos de los criterios establecidos en los documentos expuestos en el apartado anterior. En concreto se examinan las cuestiones relativas a selección y carrera; ejercicio libre del cargo e inamovilidad hasta alcanzar la edad de jubilación; y, por último, remuneración, formación y evaluación del desempeño

El texto termina con los capítulos séptimo (deberes y responsabilidades) y octavo (ética judicial). En el primero se exponen los deberes de los jueces vinculados al aseguramiento de un juicio justo y el régimen mínimo de la responsabilidad. La responsabilidad civil por daños y la disciplinaria en el ejercicio de la función ha de limitarse a casos de malicia y negligencia grave. La responsabilidad penal será solo exigible en casos de dolo. El procedimiento disciplinario ha de ser realizado por la autoridad independiente o por un tribunal y con todas las garantías del juicio justo, incluida la de recurrir ante los tribunales. En todo lo no relacionado con el ejercicio de la función jurisdiccional los jueces han de ser responsables igual que cualquier otro ciudadano. En el último capítulo se recuerdan las obligaciones éticas de los jueces, se recomienda la aprobación de un código ético y se sugiere la creación de un órgano específico al que los jueces puedan elevar peticiones de consejo en situaciones dudosas.

\section{c) La Magna Carta de los Jueces}

Exactamente el mismo día en que se aprueba la recomendación, el 17 de noviembre de 2010, y en el mismo lugar (Palais de l'Europe de Estrasburgo) el CCJE adopta la Carta Magna de los Jueces. La reunión conmemoraba los 10 años de funcionamiento del CCJE y el texto aprobado sintetiza y codifica las conclusiones de los informes adoptados durante ese tiempo. No deja de ser significativo que la inmensa mayoría de este texto, subtitulado "principios fundamentales», se dedique precisamente a la independencia judicial.

El texto en sí mismo no añade elementos diferentes a los ya enumerados en los apartados anteriores, pero eso no es óbice para conferirle un valor relevante. Es 
el documento complementario a la Recomendación aprobado por el órgano consultivo del CoE exclusivamente formado por jueces. El texto se articula en siete aparatados y 25 párrafos.

En primer lugar, el texto configura los elementos básicos de la independencia en torno a la idea de que esta, junto a la imparcialidad, es un presupuesto indispensable del funcionamiento de la justicia y la encuadra en tres dimensiones: estatutaria, funcional y económica. Apunta una idea que a menudo va a aparecer en los textos posteriores relativa al deber de cada juez de promover y preservar la independencia judicial. Igualmente enumera y desarrolla mínimamente (y sin apartarse de los documentos ya examinados) los ámbitos en los que se debe garantizar la independencia: la selección, el nombramiento hasta la jubilación, la promoción la inamovilidad, la formación, la inmunidad, la responsabilidad disciplinaria, la remuneración y la financiación del poder judicial. La Carta opta claramente por la instauración de un Consejo de Justicia para canalizar la independencia frente a otros poderes del Estado y para que se le confieran las más amplias competencias en el estatuto de los Jueces, y en la organización y funcionamiento del poder judicial, así como en la defensa de la confianza ciudadana en la administración de justicia. No falta tampoco la inevitable referencia a la composición exclusiva o por una mayoría sustancial de jueces elegidos por sus pares.

El texto presenta como novedad un apartado abordando el principio de acceso a la justicia y transparencia como parte esencial de esta Carta Magna.

Por último, el texto contiene su habitual apartado relativo a los deberes deontológicos de los jueces para, sin solución de continuidad, examinar la responsabilidad (disciplinaria y por daños) de los jueces y sus garantías, posiblemente mezclando, como en otros textos, dos ámbitos que debieran permanecer separados. Quizás aquí la única novedad sea una expresa mención a la obligación de los Estados de crear un sistema recursos para compensar los errores judiciales por parte de los poderes públicos.

\section{La actividad posterior de los órganos consultivos del CoE}

Los tres textos recién citados (la Recomendación (2010)12, el informe sobre independencia judicial de la Comisión Venecia y la Magna Carta de los Jueces) constituyen la triada básica de la definición de la independencia judicial en el soft law del CoE. Pero la actividad sobre la materia ha continuado en la labor de los órganos consultivos. Conviene resumirla brevemente.

\section{a) La Comisión de Venecia: la compilación y la Checklist del Estado de Derecho}

La Comisión de Venecia ha desempeñado desde 2010 una labor extremadamente poco conocida y casuística en la materia mediante el desarrollo de sus 
funciones consultivas, a instancias de diferentes sujetos y órganos del CoE, ante reformas legislativas o constitucionales relativas al poder judicial de los Estados miembros. Esta labor, como ya se ha apuntado, era ya relevante antes de 2010, pero se ha incrementado geométricamente desde entonces. Resulta muy difícil evaluar su impacto en las reformas, aunque ciertamente los grandes supuestos problemáticos respecto a la independencia judicial han recibido una constante respuesta en informes específicos de la Comisión. Los casos de Ucrania ${ }^{15}$, Hungría ${ }^{16}$ o Polonia ${ }^{17}$, son sin duda los más conocidos en nuestro entorno; pero basta con examinar someramente los informes emitidos y sus temáticas en la página web de la Comisión para comprobar su incansable actividad. A través de este mecanismo se ha ido creando una pléyade de informes que ha servido, como tendremos ocasión de comprobar, como un elemento básico de valoración de la situación de la independencia judicial en cada país. De este modo los informes de la Comisión se han convertido en un instrumento no solo de desarrollo de los estándares, sino también, y sobre todo, de aplicación de los mismos de manera preventiva ante las reformas judiciales en los Estados.

De dicha actividad es buena prueba el documento publicado en marzo de $2015^{18}$, reformulado y actualizado en diciembre de $2019^{19}$ en el que se compilan de manera ordenada las Opiniones e Informes de la Comisión de Venecia relativos a Tribunales y Jueces. Se trata de una compilación. Es, pues casuística y condicionada por las circunstancias concretas de tiempo y lugar en las que fueron emitidos los informes. Pero constituye una indudable fuente de conocimiento acerca de la posición de la Comisión en los grandes temas en los que ha sido llamada a pronunciarse en más de 121 opiniones o informes por países entre diciembre de

15 Respecto a Ucrania pueden consultarse entre otras las siguientes opiniones relativas a distintas reformas judiciales: CDL-AD(109)027; CDL-AD(2017)026; CDL-AD(2017)020; CDL-AD(2017)034; CDL-AD(2015)043; CDL-AD(2015)027; CDL-AD(2015)026; CDL-AD(2015)013; CDL-AD(2015)007; CDL-AD(2013)034; CDL-AD(2013)014; CDL-AD(2011)033; así como el inicio de los problemas con las sucesivas opiniones en CDL-AD(2010)003.

16 Así el durísimo primer informe CDL-AD(2012)001 sobre la reforma judicial húngara que siguió a la reforma constitucional de 2010 (y que en última instancia acabará generando el caso Baka c. Hungría examinado más adelante). Igualmente relevante serán los informes sobre la reforma del Tribunal Constitucional (CDL-AD(2012)009); la reforma del estatuto jurídico de los magistrados y la concentración de poderes en el presidente del Consejo (CDL-AD(2012)001). Las reformas introducidas como consecuencia de los anteriores informes tampoco pasaron totalmente el filtro de la comisión (CDL-AD(2012)020).

17 Comenzando por los informes sobre la reforma del tribunal constitucional polaco (2016)001 y CDL-AD(2016)026), siguiendo por con la opinión en el caso de la reforma del Consejo de Justicia (CDL-Ad(2017)031) y terminando con la opinión urgente sobre la organización de los tribunales de Derecho Común, Tribunal Supremo y otras leyes (CDL-AD(2020)002).

18 European Commission for Democracy Through Law (Venice Commission); Compilation of Venice Commission Opinions and Reports concerning Courts and Judges; de 5/03/2015, CDL-PI(2015)001.El document estaba actualizado a diciembre de 2014.

19 European Commission for Democracy Through Law (Venice Commission); Compilation of Venice Commission Opinions and Reports concerning Courts and Judges de 11/12/2019. CDL-PI(2019)008. Actualiza las opiniones hasta junio de 2019. 
1993 y junio de 2019 (además de los dos informes ya mencionados sobre nombramientos judiciales de 2007 y sobre independencia judicial de 2010) ${ }^{20}$.

Los temas sistematizados, a estas alturas de la exposición, no pueden sorprender. En primer lugar, se abordan las normas relativas al nivel al que han de regularse las diferentes cuestiones (nombramiento, cese, remuneración y estatus; tribunales y su estructura; Consejos Judiciales). En segundo lugar, se compilan los informes relativos a la posición de los jueces individuales. Se aborda la definición de independencia e imparcialidad, nombramiento de los jueces (criterios, incompatibilidades y órganos/procedimientos de nombramiento), carrera judicial (duración, jueces provisionales, evaluación y promoción) responsabilidad (inmunidades, responsabilidad disciplinaria y reglas deontológicas), inamovilidad (traslados, ceses anticipados y responsabilidad criminal), jubilación, remuneración, y personal no judicial desempeñando funciones judiciales. En tercer lugar, se sistematizan informes relativos a tribunales: creación y organización de tribunales, organización interna de los tribunales, relaciones entre tribunales superiores e inferiores, reparto de casos, traspaso de casos entre jueces, presidentes de órganos colegiados (nombramiento, duración del mandato y reelección, competencias), reparación de dilaciones indebidas, autonomía financiera y de personal. Por último, la compilación recoge las aportaciones de los informes respecto a los Consejos de Justicia; funciones y obligaciones, composición, equilibrio entre miembros judiciales y legos, representación del ejecutivo en el Consejo, representación de la sociedad civil, cualificación de los candidatos, incompatibilidades y cuotas, presidencia y vicepresidencia del Consejo, estructura y adopción de decisiones; nombramiento y estatus de los miembros, y otros órganos reguladores.

Junto a esta labor de informe, la Comisión ha tenido ocasión de emitir también valoraciones temáticas más generales relevantes para estas páginas. En particular conviene destacar el Informe sobre Estado de Derecho ${ }^{21}$ adoptado el 4 de abril de 2011 y que ha dado lugar a la muy conocida «Checklist» sobre Estado de Derecho ${ }^{22}$.

El informe no tiene por objeto la independencia judicial propiamente, sino el Estado de Derecho. En este contexto se realiza un indudable esfuerzo por sentar las bases comunes de este concepto en el marco europeo (párrafo 16) considerándolo un elemento inherente de toda sociedad democrática en virtud de la cual todo ser humano ha de ser tratado con dignidad, igualdad y racionalidad y de

20 Es significativo señalar que el periodo 1993-2010 incluye casi tantas opiniones (43) que el periodo 2010-2014 (39) lo que denota el significativo aumento de la labor de la Comisión en general y de la importancia de la cuestión judicial en su labor.

21 European Commmission for Democracy Through Law (Venice Commission); Report on the Rule of Law, de 4/04/2011. CDL-AD(2001)003.

22 La Checklist es incluida en el informe recién citado como anexo y es desarrollada en un documento posterior: European Commmission for Democracy Through Law (Venice Commission); Rule of Law Checklist, CDL-AD(2016)007, de 18/03/2016. 
acuerdo con la ley por los poderes públicos. Además, continúa la definición, los ciudadanos han de tener la posibilidad de cuestionar sus decisiones ante tribunales independientes e imparciales de acuerdo con procedimientos justos. El Estado de Derecho se referirá por tanto al ejercicio del poder y a la relación entre los ciudadanos y el Estado.

Desarrolla la cuestión estableciendo los elementos esenciales de tal concepto en torno a seis ejes: 1) Supremacía del Derecho; 2) Seguridad jurídica; 3) Prohibición de la arbitrariedad; 4) Acceso a la jurisdicción ante tribunales independientes e imparciales; 5) Respeto a los derechos fundamentales; 6) No discriminación e igualdad ante la ley.

Como ha señalado $\mathrm{Craig}^{23}$, comentando este informe para su aplicación a la crisis de Estado de Derecho actual en la UE, los seis elementos interpelan directamente a la garantía de la independencia judicial si bien es en el cuarto de ellos donde tal interacción es más inmediata. En tal sentido el propio informe subraya que el papel del poder judicial en un Estado de Derecho es esencial y por ello su independencia ha de ser garantizada. Garantía que ha de extenderse incluso a las apariencias pues estas son esenciales para asegurar la confianza de los ciudadanos en la justicia. Además abarcará elementos tan importantes como el carácter público de los juicios, el respeto al plazo razonable, el asesoramiento gratuito, la existencia de una fiscalía autónoma, la eficacia de las sentencias o la fuerza de la cosa juzgada.

Un objetivo esencial del informe era permitir al CoE contribuir a la implantación en la práctica del Rule of Law en los Estados y con la colaboración de éstos. Por ello aprueba una Checklist (lista de verificación) del grado de vigencia del Estado de Derecho en los Estados miembros. Checklist que va a ser clave en las evaluaciones posteriores llevadas a cabo por el $\mathrm{CoE}$ en la materia fundamentalmente a través de la propia Comisión de Venecia.

La checklist es desarrollada en $2016^{24}$ mediante un documento que destaca el carácter evolutivo del concepto y la necesidad de su adaptación a diferentes contextos legales y fácticos ${ }^{25}$. El documento desarrolla pormenorizadamente la lista de cuestiones para evaluar el nivel de protección del Estado de Derecho en cada país.

La lista agrupa en cinco grandes grupos los aspectos básicos y formula las preguntas concretas objeto de evaluación. Los grupos son: a) Legalidad (supremacía

23 P. Craig, «Definition and conseptualisation of the Rule of Law and the role of Judicial Independence therein» en Rule of Law in Europe. Perspectives from practitionaers and Academics; EJTN, Bruselas, 2019.

24 European Commission for Democracy Through Law (Venice Commission), Rule of Law Checklist. Study n. ${ }^{\circ} 71172013$, de 18/03/2016, CDL-AD(2016)007.

25 No deja de ser interesante cómo el propio informe destaca la existencia de una aproximación diferente, pero muy similar, al concepto de Estado de Derecho en el caso de la UE que ha conducido a su configuración jurisprudencial como un principio general de su propio ordenamiento jurídico. Para el TJUE, continúa la Comisión, tal principio incluye: la supremacía del Derecho, el equilibrio institucional, la revisión judicial de las decisiones; derechos fundamentales procesales, incluido el derecho a un recurso efectivo así como los principios de igualdad y proporcionalidad (Venice Commision CDL-AD(2016)007, párrafo 42). 
de la ley, cumplimiento de la ley; relación entre derecho nacional e internacional; poderes normativos del poder ejecutivo; procedimientos de elaboración de las leyes; excepciones en situaciones de emergencia, deber de respetar la ley; actores privados en cargos con funciones públicas) b) Seguridad Jurídica (accesibilidad de la legislación; accesibilidad de la jurisprudencia; previsibilidad de las leyes, estabilidad y coherencia de las leyes, expectativas legítimas, no retroactividad, principio de legalidad penal, res judicata) c) Prevención del abuso de poder; d) Igualdad ante la ley y no discriminación (previsión constitucional, no discriminación, igualdad en la ley) y, e) Acceso a la Justicia (independencia e imparcialidad -incluyendo independencia del poder judicial, independencia de los jueces individuales; imparcialidad; autonomía y control de la fiscalía, independencia e imparcialidad de la abogacía—, derecho a un juicio justo —incluiría a su vez, acceso a los tribunales, presunción de inocencias, otros aspectos del derechos a un juicio justo, efectividad de las decisiones judiciales- y justicia constitucional).

Evidentemente en este elenco de ítems las referencias a diferentes aspectos de la independencia judicial son innumerables y diseñan un mapa bastante claro de los aspectos claves de la misma para la Comisión y constituye un punto de referencia compartido en la definición no solo del Rule of Law en Europa, sino también de la garantía de la independencia judicial. Se ha convertido con el tiempo en un instrumento básico de evaluación de la salud del Estado de Derecho en Europa y no solo en el CoE, sino también en la $\mathrm{UE}^{26}$, aunque haya recibido críticas fundadas por el uso torticero que de la misma han hecho algunos Estados en su deriva iliberal ${ }^{27}$

\section{b) EL CCJE}

De las 10 opiniones emitidas por el CCJE en el periodo 2010-2019, nos interesa especialmente la opinión n. ${ }^{\circ} 18$ (2015) «sobre la posición del poder judicial y su relación con los demás poderes del Estado en una democracia moderna $»^{28}$. En ella se abordan directamente cuestiones esenciales respecto a la definición de la independencia judicial externa. El informe reconoce los problemas planteados en algunos países europeos respecto al poder judicial como contrapeso a poderes democráticos. Se subraya que el poder judicial ha tenido en las

26 Véase A. Drzemcbzewski, «Le Conseil d l'Europe et l'État de droit: A propos de la liste des critères de l'État de droit élaborée par la Commission de Venise», Revue Universelle des Droits de l'Homme, 2017, pp. $14 \mathrm{y}$ ss.

27 En concreto la profesora K.L. SCHEPPELE, «Worst practices and the Transnational Legal Order or How to build a Constitutional "Democratship" in Plain Sight» Working Paper 2016, https://perma.cc/ Q266-MJEK apunta cómo estos Estados han aplicado un auténtico catálogo de «malas prácticas» toleradas por las instituciones supraestatales a partir de esta checklist.

28 CCJE: Informe n. ${ }^{\circ}$ 18(2015). La posición del Poder Judicial y su relación con los demás poderes del Estado en una democracia moderna. 16/10/2015, CCJE(2015)4. 
últimas décadas que desarrollar una labor de control cada vez más fuerte sobre los otros dos poderes del Estado. De este modo para la opinión pública, para la sociedad o incluso para los otros poderes del Estado, el poder judicial se habría convertido en una suerte de «arena democrática alternativa». No es ajeno el informe, y así se explicita, a la existencia de regresiones en la configuración estatal de la separación de poderes; en particular referentes a la influencia excesiva del ejecutivo y los ataques políticos a las resoluciones judiciales.

El análisis contenido en la opinión incide de manera esencial en que la ubicación del poder judicial como independiente respecto a los poderes «políticos» del Estado es una condición esencial del Estado de Derecho y genera la necesidad de acentuar su legitimidad. Dicha legitimidad, se sostiene, aunque no con esos términos, es tanto de origen, como de ejercicio. La legitimidad de origen se encuentra en la Constitución y en el ordenamiento jurídico. La legitimidad de ejercicio solo podrá obtenerse si se consigue la confianza pública en el trabajo de los jueces y tribunales lo que a su vez conduce a altos niveles de exigencia respecto a la calidad del trabajo realizado y la ejemplaridad personal en el comportamiento.

En este punto la idea clave es que la legitimidad de ejercicio del poder judicial solo puede obtenerse a través de la rendición de cuentas como expresión de un elemento democrático básico, por un lado, y demostración del sometimiento del juez a la ley, por el otro. La responsabilidad/rendición de cuentas va a adoptar dos fórmulas. La responsabilidad explicativa que implica la justificación de las propias acciones y se va a ejercer mediante distintos mecanismos como la publicidad del proceso, el debate con otros poderes del Estado, el diálogo con la sociedad, etc. La responsabilidad punitiva habrá de respetar las garantías de inamovilidad y permanencia esenciales para asegurar la independencia judicial. Este es un elemento clave que el CCJE resalta: la exigencia de legitimidad y con ello de la obligación de rendición de cuentas no ha de afectar negativamente al núcleo de las garantías de la independencia judicial y que el informe centra en una serie de principios ya bien conocidos. En concreto: la inamovilidad, el nombramiento y promoción sin injerencias políticas, remuneración suficiente y la seguridad vital y patrimonial.

La propuesta de articulación de las relaciones entre poderes realizada en la opinión resulta, quizás, un poco naif. Realmente la única solución que ofrece a la adecuada ubicación de un poder judicial independiente es la aplicación de un voluntario self-restraint en la actividad de los diversos poderes. En concreto respecto al poder judicial sugiere que no excedan del ámbito legítimo del ejercicio de sus funciones, que evite el exceso de corporativismo o de autodefensa (en especial escudarse en la independencia para oponerse a cualquier reforma del sistema judicial). Sin embargo, en una afirmación que aparece en ocasiones en los textos examinados pero que no constituye claramente un estándar europeo (aún), cuando las reformas «supongan una amenaza o ataque a la independencia judicial o a la capacidad del poder judicial para cumplir su función constitucional, este debe 
defender su postura de modo contundente». A los poderes «políticos» del Estado, el CCJE va a pedir también respeto y self-restraint. En sus peticiones, mucho más pormenorizadas que las dirigidas al poder judicial, resuenan los evidentes ecos de los problemas de Rule of Law existentes en ciertos Estados europeos. Sugiere no cuestionar en ningún caso el nombramiento de jueces ya seleccionados ni mucho menos su destitución o cese; evitar los cambios frecuentes de legislación; prohibir comisiones de investigación cuando existan procesos judiciales en curso; alejar la administración e inspección de tribunales del control del poder ejecutivo; garantizar la autonomía presupuestaria; y considerar las críticas «exageradas» al poder judicial por miembros de los otros poderes como un ataque intolerable a la independencia judicial merecedora de respuesta por parte del propio poder judicial. En fin dos recomendaciones no por evidentes resultarán menos importantes: los poderes legislativo y ejecutivo han de proteger a los jueces y tribunales de las amenazas físicas o intimidaciones y, en ningún caso, pueden fomentar la desobediencia de las resoluciones judiciales y menos aún la violencia contra los jueces.

\section{RECAPITULACIÓN: LOS ESTÁNDARES EUROPEOS SOBRE INDEPENDENCIA JUDICIAL}

Tras el examen de todos estos textos conviene tratar de ofrecer una visión global y básica de la posición del CoE respecto a la independencia judicial. Esta visión podría resumirse en las siguientes conclusiones parciales.

Primera: la independencia judicial ha de estar reconocida en las constituciones de los Estados miembros en lo referido a sus elementos más básicos. El desarrollo de los mismos ha de ser realizado primariamente mediante una norma con rango de ley. Tal y como se sostiene en los informes de la Comisión Venecia respecto a las reformas húngaras, el uso de estos instrumentos no ha de ser meramente formal, sino que ha de conseguirse un amplio consenso entre todos los grupos políticos relevantes, evitando la mera imposición de la mayoría sobre las minorías.

Segunda: la independencia judicial tiene una dimensión objetiva y una dimensión subjetiva. En la primera se concibe como una cualidad indispensable del poder judicial propio de un Estado basado en el rule of Law. En la segunda se trata de un derecho de todo justiciable para obtener un juicio justo. Por tanto, la independencia no es un fin en sí mismo, ni un privilegio de los jueces. Es un principio tendente a garantizar elementos básicos del Estado de Derecho y de los derechos de los ciudadanos.

Tercera: la independencia supone la interdicción de la presión indebida sobre los jueces sin referencia al proceso del que estén conociendo. En este punto es en el que se diferenciaría (al menos teóricamente) de la imparcialidad que se refiere a la prohibición de las presiones y prejuicios presentes en relación a las partes o a los intereses en conflicto en un concreto proceso judicial. Las presiones frente a las 
que ha de estar protegido el juez pueden proceder de otros poderes del Estado o de otros sujetos (independencia externa) o del seno del propio del poder judicial por presión de órganos superiores, presidentes de tribunales o incluso consejos judiciales (independencia interna).

Cuarta: la independencia judicial puede garantizarse mediante la creación de un Consejo Judicial. El CoE es claramente partidario de ellos como órganos ajenos a los otros poderes del Estado para canalizar la independencia judicial. La composición y funciones de estos órganos han de reflejar esta finalidad básica. Para ello, en los documentos del CoE, se recomienda que la mayoría de sus miembros han de ser jueces elegidos por sus pares. Han de evitarse todo tipo de posibles condicionamientos políticos en el nombramiento, funcionamiento o cese de los Consejos. Sus funciones han de orientarse a asegurar la posición del juez frente a cualquier presión externa tanto desde la defensa de su independencia individual como desde la del poder judicial en su conjunto. Por ello, desempeñará competencias esenciales en todas las cuestiones relativas al estatuto de los jueces y magistrados, entre otras.

Quinta: la independencia judicial condiciona de manera determinante el estatuto jurídico de los jueces y magistrados. En este sentido todos los elementos claves del mismo han de defender la independencia del juez y del propio poder judicial en su conjunto. Por tanto ha de garantizarse la ausencia de presiones externas (con distintos mecanismos) en su selección, nombramiento, promoción y cese; en sus incompatibilidades generales y referidas a casos concretos; en el libre ejercicio de su cargo (con especial referencia a la inamovilidad y al reparto de asuntos) y desarrollo de la carrera profesional; en la remuneración; en la responsabilidad (civil, penal y disciplinaria) en el ejercicio de su cargo; y en la importancia de la tutela del asociacionismo judicial tanto nacional como internacional.

Sexta: la independencia judicial ha de ser asegurada por los propios jueces. Todas las decisiones de los poderes públicos (judiciales o no) atinentes a la independencia judicial han de fundarse en criterios objetivos, preestablecidos y transparentes susceptibles de revisión judicial. La posibilidad de revisión judicial de las decisiones que afecten a la independencia se convierte por tanto en un rasgo esencial y de carácter horizontal plasmado en cualquiera de sus manifestaciones.

Séptima: la independencia judicial ha de ser percibida por los ciudadanos. La independencia es, pues, también una cuestión de apariencias. No ha de entenderse ello como irresponsabilidad. Los jueces y tribunales han de rendir plena cuenta de sus actos ante los ciudadanos a través de diferentes instrumentos que han de evitar convertirse en mecanismos de presión sobre sus decisiones. En tal sentido resultará básico el respeto mutuo entre poderes $\mathrm{y}$, en particular, la interdicción de los ataques excesivos (que no la crítica) que puedan menoscabar la confianza de los ciudadanos en la independencia judicial. Ante ataques frontales a la independencia judicial parece abrirse paso la idea en los documentos del CoE de la existencia de un deber de defensa de la misma no ya de los órganos específicamente creados para ello, sino incluso de los propios jueces individuales. 
Octava: la independencia judicial no solo condiciona el estatuto jurídico de los jueces y magistrados, sino también su estatuto deontológico. El CoE apoya claramente el desarrollo de normas de conducta ética e instrumentos de autocontrol deontológico tendentes a garantizar la máxima ejemplaridad, especialmente en la apariencia de independencia, en el poder judicial. Ejemplaridad tendente a incrementar la confianza en la justicia independiente necesaria en un Estado de Derecho.

\section{LA CRECIENTE EFICACIA (INDIRECTA) DE LOS ESTÁNDARES EN MATERIA DE INDEPENDENCIA}

Ciertamente, determinar cuál ha sido la eficacia de los estándares establecidos en el acervo recién resumido resulta muy complicado. El soft law internacional, por definición, inspira más que vincula la actuación de otros órganos tanto internacionales como, sobre todo, nacionales que lo incorporan a sus decisiones de una manera más o menos expresa y en diferente grado. Analizar su eficacia en los ordenamientos jurídicos nacionales de los 47 Estados miembro del CoE resultaría una tarea imposible en estas páginas. Pero sí podemos tratar de recoger su influencia en las instituciones de las dos grandes organizaciones de la integración europea.

\section{La influencia en la jurisprudencia del TEDH}

En el ámbito del CoE, el TEDH es el órgano en el que más nos interesa resumir la influencia del soft law. Pero conviene apuntar que esta labor se antoja complicada y las conclusiones que se van a apuntar han de tomarse con cierta cautela por dos motivos básicos. Se refiere el primero a que se produce una suerte de discurso circular entre el Tribunal y el resto de los órganos políticos y/o consultivos del CoE. Efectivamente no puede desconocerse que los documentos conformadores del soft law adoptan como punto de partida y de referencia permanente la jurisprudencia del TEDH. De este modo la concretan y expanden a los diferentes temas abordados. Con posterioridad el propio TEDH, al volver sobre casos relacionados, utiliza dichos documentos e inspira futuros desarrollos. Se crea así un círculo permanente de retroalimentación mutua que hace muy difícil establecer quien influye sobre quién en la construcción de los distintos conceptos. Pero además, y este sería el segundo motivo, el TEDH no cita necesariamente las fuentes de soft law en sus decisiones, aunque se aprecie una perfecta sintonía ${ }^{29}$ entre sus

29 Coherencia que lleva a algunos autores a afirmar que el CoE a través del TEDH y de sus órganos políticos y consultivos ha optado por un determinado modelo de poder judicial. Pueden consultarse así los diversos trabajos publicados por D. Kosař desde 2013, en especial, «Nuding Domestic Judicial Reforms form Strasbourg: How the European Court of Human Rights shapes domestic judicial design», Utrecht Law Review, vol 13, n. ${ }^{\circ} 1,2017$, pp. 111 y ss. 
sentencias y los documentos componentes del mismo, de modo que no se pueda dilucidar si el contenido de la jurisprudencia es un desarrollo exclusivo del anterior case law o la incorporación de nuevos estándares a partir de dicho soft law.

Con carácter general el uso (expreso) que ha hecho el TEDH del soft law ha sido tardío y en un determinado tipo de jurisprudencia sobre la independencia judicial. Tardío porque pese a que los primeros documentos (muy singularmente la primera Recomendación) datan de principios de la década de los 90 del pasado siglo, no va a citarlos por primera vez hasta 2004, en concreto en Zubko y otros c. Ucrania. Sin embargo, el uso no se generaliza hasta 2012. A partir de esa fecha y con creciente frecuencia el TEDH los nombra expresamente con bastante asiduidad y, como tendremos ocasión de observar, especialmente en leading cases. Puede apreciarse de nuevo cómo es a partir de 2010 que los órganos del CoE comienzan a desarrollar verdaderamente la cuestión de la independencia judicial.

Muy relevante es destacar que este uso se produce en los recursos interpuestos por magistrados europeos que consideraban lesionados sus derechos como consecuencia de la falta de respeto a su independencia y no en los casos relativos a reclamaciones individuales por violación del derecho al juez independiente del art. 6.1 CEDH. De este modo, la influencia (al menos la expresa) de los documentos del soft law se plasma en las dimensiones estatutaria y objetiva de la independencia judicial y no en su dimensión subjetiva.

Siguiendo la estructura de las vías de influencia de los documentos no vinculantes del CoE en el TEDH apuntada por López Guerra, el uso de dicho derecho en las decisiones adopta tres formas básicas.

La primera e indudablemente más suave es la que a menudo se realiza en los votos particulares. En este tipo de supuestos la referencia a esos documentos tiene como objetivo apuntalar y dotar de autoridad externa la posición del firmante del voto sin tener ningún tipo de eficacia inmediata real. Al menos demuestran que en la deliberación se utilizaron y tuvieron alguna relevancia. Ejemplos paradigmáticos en el tema que nos ocupan son los muy elaborados particulares del Juez Sicilianos en Baka c. Hungría (Gran Sala) y el de Pinto de Alburquerque en esa misma sentencia y en Ramos Nunes de Carvalho e Sác. Portugal (Gran Sala).

La forma más habitual de citar los textos integrantes del soft law en la jurisprudencia del TEDH es en el apartado en el que se resumen la normativa aplicable y en especial la internacional. Bajo distintos títulos («documentos internacionales relevantes» o bien «documentos del Consejo de Europa») el Tribunal selecciona los textos que son importantes para la resolución de la controversia. De este modo aparece citada en Zubko y otros c. Ucrania (pars 41-43), Harabin c Eslovaquia (pars. 104-110), Oleksander Volkov c. Ucrania (pars. 78-80), Baka c. Hungría (tanto en Sala — pars. 47 a 65- como en Gran Sala — 57 a 71 y 77 a 81-), Mitrinovski c la antigua república yugoslava de Macedonia (pars. 52-56), Draft - OVA A.S. c Eslovaquia (pars. 58-59), Miracle Europa c Hungría (pars 26-27), Ramos Nunes de Carvalbo e Sá c. Portugal (en Gran Sala - par. 83-, pero sobre todo en Sala — 42 a 49-), Çatal c. Turquía (par. 21), Denisov c. Ucrania 
(Gran Sala, pars. 33-35), Thiam c. Francia (pars 36-30), y J.B. y otros c. Hungría (pars. 37 a 40$)^{30}$.

En tercer lugar, y siempre siguiendo el método de análisis propuesto por López Guerra, la fórmula en la que resulta más clara la influencia del soft law en la jurisprudencia se muestra en aquellos supuestos en los que el TEDH incluye las referencias en la fundamentación jurídica de su decisión. Estos casos, en lo referido a independencia judicial, son menos numerosos pero son muy relevantes. Así se cita en Zubko y otros c. Ucrania (par. 68); Oleksander Volkov c. Ucrania (pars 112 a 114 y 174), Baka c. Hungría (en Gran Sala, pars 117 y 146-148, y en Sala, par. 94), Miracle Europa c Hungría (par. 61), Ramos Nunes de Carvalbo e Sá c. Portugal (Sala, par. 75), Denisov c. Ucrania (Gran Sala, par. 68) y Thiam c. Francia (par. 82).

Del uso realizado en estas sentencias cabe destacar algunos elementos significativos. El primero es sin duda que el soft law está presente en los tres leading cases en materia de defensa de la independencia judicial en Europa como son Volkov, Baka y Nunes de Carvalho. Aunque no de la misma forma. Efectivamente, es destacable cómo las referencias al soft law son muy relevantes en los dos primeros. Sin embargo, las referencias desaparecen prácticamente en la sentencia de Gran Sala en Nunes de Carvalho (en la que simplemente se hace una referencia a Baka y a Volkov en la descripción de la documentación relevante) después de que la Sala se hubiera detenido en su examen en la determinación del derecho aplicable y sobre todo se hubiera apoyado en ella en la fundamentación jurídica para justificar la presencia de una mayoría de jueces en los órganos disciplinarios. No deja de ser importante que las menciones al soft law aparezcan aquí solo en el voto disidente de Pinto de Alburquerque (que considera que el conjunto del régimen disciplinario de los jueces portugueses debía haberse considerado contrario a la independencia judicial tal y como se hizo en Sala). De este modo puede apuntarse que el soft law es utilizado cuando se procede a la definición de los aspectos esenciales de la independencia judicial. Conclusión que describe de forma razonablemente clara el párrafo 68 de Denisov c. Ucrania: «En su sentencia Oleksander Volkov, la Corte formuló una serie de criterios para establecer si el Consejo Judicial como órgano disciplinario de la magistratura cumplía los requisitos de independencia e imparcialidad. Para hacerlo, la Corte se apoyó en su jurisprudencia anterior y tomó en cuenta los textos internacionales relevantes, en especial las opiniones y recomendación de otros órganos del Consejo de Europa».

Igualmente debe notarse el uso del Tribunal de informes específicos de la Comisión de Venecia referidos a los Estados demandados tanto para establecer elementos fácticos (muy claramente en Baka c. Hungría en la que tales informes sirven para establecer la relación de causalidad entre las declaraciones del recurrente en

30 No incluimos la sentencia Kövesi c. Rumanía porque aún utilizando alguno de los instrumentos citados en el texto se refiere y se centra sobre todo en el tema de la independencia de los fiscales. 
contra de las reformas judiciales y su cese como presidente del consejo judicial mediante una reforma de la Constitución) como jurídicos (la defectuosa configuración legal del Consejo judicial en Volkov c Ucrania y en Miracle Europa c. Hungría).

Por lo demás el Tribunal hace un uso del soft law de manera muy concreta en dos casos para «importar» criterios específicos del mismo en su jurisprudencia en ausencia de previa jurisprudencia en casos que abordan cuestiones muy delicadas. Tales serían los supuestos de Zubko y otros c. Ucrania (para establecer como un elemento esencial la remuneración suficiente y legalmente prestablecida de los jueces y magistrados) y Thiam c. Francia (para justificar que la intervención del Presidente de la República en el nombramiento de los jueces no constituye per se una agresión a la independencia judicial que vicie los derechos de la otra parte en un proceso civil en el que aquél es una parte demandante).

En definitiva parece deducirse de este breve repaso que el TEDH ha utilizado el soft law cuando ha necesitado resolver supuestos en los que debía hacer un control bastante intenso de los ordenamientos nacionales en lo referido a la garantía de la independencia judicial de los Estados miembros. Cuando dicho control no ha sido tan acusado, si se quiere invasivo de la autonomía de organización de los Estados, el TEDH o bien simplemente lo ha citado con carácter general o bien lo ha omitido. El distinto planteamiento en la mucho más intervencionista sentencia de Sala en Ramos Nunes de Carvalho e Sá frente a su corrección (con un control menos intenso) en Gran Sala tendría pues una explicación razonable.

Esta conclusión parece confirmarse claramente en la reciente y seminal sentencia de Gran Sala Guðmundur Andri Ástrádsson c Islandia de 1 de diciembre de 2020. En este caso el uso realizado del soft law no solo es muy numeroso, tanto en los antecedentes como en la fundamentación jurídica, sino determinante del resultado. En concreto se utilizan la Recomendación (2010)12, el informe de la Comisión de Venecia sobre independencia judicial y sobre Estado de Derecho; la Carta Europea del Estatuto de los Jueces y, por primera vez, las opiniones del CCJE. Pero lo más novedoso estriba en que tales informes son utilizados con dos finalidades diferentes. Por un lado, para definir el concepto de «tribunal» y su vinculación con la garantía de la independencia en el proceso de nombramiento de los jueces (pars. 220 a 222 y 227). Por el otro, y más importante, el uso de las opiniones del CCJE se utiliza para justificar la intensidad del control que puede ejercer el TEDH para evaluar el respeto de la legislación reguladora del nombramiento de los jueces por parte de las autoridades nacionales cuando ha existido un control judicial nacional previo. De este modo, el TEDH se apoya en este soft law para justificar la necesidad de establecer un nuevo test de supervisión del control judicial nacional de la aplicación de la ley reguladora de los nombramientos judiciales (par 239).

\section{La influencia en la UE}

La presencia del soft law del CoE sobre la UE ha seguido un camino diferente. 
Es cierto que puede apreciarse una influencia indirecta en la jurisprudencia del Tribunal de Justicia a través de la recepción del case law de Estrasburgo. Influencia indirecta que se puede observar con claridad en la referencia a dicho soft law en las últimas conclusiones de los Abogados Generales en materia de independencia judicial ${ }^{31}$. Pero en general se trata de una influencia «oculta» en la medida en que las resoluciones no descansan de manera expresa en dicho ordenamiento no vinculante ${ }^{32}$.

Mucho más interesante para estas páginas es la influencia ejercida a través de su uso por los órganos políticos de la UE, muy especialmente la Comisión, en la determinación del respeto a los elementos básicos del Estado de Derecho en los Estados miembros.

\section{a) Influencia inicial: la gran ampliación al Este y la crisis posterior}

La fecha de nacimiento de esta influencia, englobada dentro del más amplio tema de la salvaguardia del Rule of Law, se puede fijar claramente: las conclusiones del Consejo Europeo de Copenhague de 21-22 de junio de 1993 que abren el proceso de acceso a la UE de los países del Este y Centro de Europa. En ellas se formulan los llamados Criterios de Copenhague que habrán de respetar los Estados candidatos: estabilidad de las instituciones de garantía de la democracia, el Estado de Derecho, los derechos humanos y el respeto y protección de las minorías. Estos criterios incorporados al acquis comunitario suponen la incorporación de parámetros constitucionales que finalmente se incluirían en 1999 en el art. 6

31 Así aparecen por primera vez en las conclusiones del Abogado General Tanchev en el emblemático caso A.K. Se trata de las conclusiones previas a la tercera de las sentencias dictadas contra Polonia con motivo de sus reformas del sistema judicial, pero la primera que es resultado de una cuestión prejudicial y que afecta directamente al régimen disciplinario de los jueces y magistrados. Es curioso que el Abogado general, que también dictó las conclusiones en los dos recursos por incumplimiento previos no los mencionara en esos casos aunque tanto sus posiciones como los del Tribunal se situaran plenamente en la línea tanto de la jurisprudencia de Estrasburgo, como del soft law del Consejo de Europa. Se trata de las conclusiones de 27/06/2019, C585/18 (624/18 Y 625/18), A.K. (Independencia de la Cámara disciplinaria de la Corte Suprema), ECLI:EU:C:2019:551. Con posterioridad las citas se han incluido profusamente en las conclusiones del mismo Abogado General en el asunto C-824/18, A.B y otros (nombramiento de los jueces del Tribunal Supremo, Recursos) de 17/12/2020, ECLI:EU:C:2020:1053; en las del Abogado General Bobeck en los asuntos C-83/19, C-127/19, C-291/19 y C-355/19 en diversos casos respecto a Rumanía, de 23/09/2020, ECLI:EU:C:2020:746 (aunque en este caso la mención a la Comisión de Venecia ya se planteaba en la formulación de la cuestión por el juez nacional), y en las del Abogado General Hogan en el asunto C-896/19, Reppublika, de 17/12/2020, ECLI:EU:C:2020:1055; en las que, además ya se cita Guðmundur Andri Ástráłsson c Islandia dictada apenas 15 días antes. Estas citas en los casos pendientes en materia de independencia judicial parecen indicar una mayor atención desde Luxemburgo al soft law de Estraburo, pero habrá de confirmarse en los muchos otros casos aún en tramitación ante el TJ.

32 Obviamente eso no significa minusvalorar tal influencia, sino solo destacar que no podemos establecer hasta qué punto ha sido relevante. La jurisprudencia del TJ en la materia desde 2018 ha sido extraordinaria tanto desde el punto cualitativo como cuantitativo. 
TUE en su versión del Tratado de Amsterdam para los Estados miembros y la UE y, sobre todo, en las condiciones de acceso a la UE en el art. 49 TUE.

Sin embargo, las menciones genéricas contenidas en esos preceptos (hoy los valores del art. 2 y la remisión genérica a los mismos del art. 49 TUE) al Estado de Derecho no conferían muchas pistas respecto a la definición de la independencia judicial exigida a los países candidatos. Según recoge SEIBERT-FOHR ${ }^{33}$, a quien seguimos de cerca en este punto, el Consejo Europeo acudió en ayuda de la Comisión durante la negociación de la adhesión en el Consejo de Justicia e Interior de mayo de 1998. En concreto sugirió a la Comisión que en sus informes sobre las negociaciones con los Estados candidatos tuviera en cuenta el CEDH, la jurisprudencia del TEDH y las resoluciones y recomendaciones del CoE para interpretar el concepto Rule of Law exigido a dichos Estados. Dado lo limitado de la jurisprudencia y de los documentos oficiales del $\mathrm{CoE}$, la Comisión fue mucho más allá y utilizó profusamente los instrumentos de soft law del CoE ya examinados. En particular la ya examinada Checklist de la Comisión de Venecia para evaluar la vigencia del Estado de Derecho adquirió una relevancia que aún hoy mantiene.

La UE, por tanto, no elaboró sus propios estándares en materia de independencia judicial de una manera ni autónoma, ni transparente. No fue autónoma porque se apoyó de manera determinante en la documentación del CoE. Y no fue transparente porque se matizaron esos estándares de manera progresiva en el marco de las negociaciones de adhesión y de los informes de la Comisión, sin que existiera una reflexión pública y amplia sobre las diferentes cuestiones planteadas por el Rule of Law en general y la independencia judicial en particular ${ }^{34}$.

De este modo los estándares del CoE se convierten en una exigencia de la estructura interna de los nuevos Estados miembros de la UE y se incorporan de una manera indirecta a la propia estructura de la UE. Esta vía de conexión genera un efecto positivo de homogeneidad en la definición del concepto en ambas organizaciones internacionales. Se ha llegado, así, a afirmar que existe un determinado modelo de poder judicial impuesto a nivel europeo en la jurisprudencia del TEDH y en el soft law de origen consultivo. Pero ello, simultáneamente, puede justificar críticas relativas a la falta de deliberación democrática previa y de transparencia en la asunción de decisiones constitucionales básicas como las relativas a la organización del poder judicial ${ }^{35}$.

33 A. Siebert-Fohr, «Judicial Independence in European Union Accessions: The Emergence of a European Basic Principle» German Yearbook of International Law, 52, 2009, pp. 418 y ss.

34 Véase A. Drzemcbzewski, ibídem, pp. 14 y ss.

35 Kosař, D. \& Bobeck, M. «Global Solution, Local Damages: A Critical Study in Judicial Councils in Central and Eastern Europe», Department of European Legal Studies, Research Paper in Law, 07,2013. la crítica se desarrolla en el conjunto del artículo pero son de especial interés las pp. 5 a 8 . Véase también KosAř, D. «Nuding Domestic Judicial Reforms form Strasbourg: How the European Court of Human Rights shapes domestic judicial design», citado más arriba. 
Sin embargo, con posterioridad la UE tuvo que enfrentarse a lo que la doctrina ha denominado el «dilema de Copenhague» ${ }^{36}$. Dicho dilema subraya que los criterios de respeto a los valores fundamentales formulados por el Consejo en dicha ciudad danesa para canalizar la ampliación hacia el Este de la UE no estuvieron bien diseñados desde un principio y que, en especial, adolecieron de mecanismos para mantener en el tiempo un sistema de control del cumplimiento de los estándares en los Estados ${ }^{37}$. Se pensaba, con un exceso de optimismo, que el acceso a altos niveles comprobados de garantía del Estado de Derecho era un camino irreversible. Por ello, los mecanismos previstos en los Tratados ante eventuales crisis de respeto a los valores del art. 2 TUE se reducen a los previstos en el art. 7 TUE que, como muestra la práctica, son extremadamente difíciles de aplicar.

La evolución ha mostrado que esa vuelta atrás o regresión en el Estado de Derecho no solo era posible, sino que se ha convertido en una realidad ante la que la UE estaba mal equipada ${ }^{38}$ y ha provocado la puesta en marcha de otros mecanismos en la defensa del Estado de Derecho en general, y de la independencia judicial en particular.

El fenómeno se manifiesta primero en el $\mathrm{CoE}$ dada su mayor amplitud y la menor intensidad de los controles ejercidos sobre los Estados antes de su ingreso. A partir de 2010 algunos de los problemas eran ya evidentes. En la UE las regresiones van a tardar más en llegar pero alcanzarán primero a Hungría (2010) y después muy claramente a Polonia (2015) amenazando con extenderse a otros Estados del centro y este de Europa sobre todo.

En el caso del CoE la reacción a estas regresiones se va a articular, como hemos visto, con una renovación generalizada del soft law sobre independencia judicial y un fortalecimiento de los órganos de monitorización y de control consultivo. Pero también con la renovación de la jurisprudencia del TEDH que comenzará a desarrollar, apoyándose en el citado soft law, las vertientes objetiva e institucional del principio de independencia judicial a partir, sobre todo, de las

36 Por todos, AGH, A. «Decline of Democracy in the ECE and the Core-Periphery Divide: Rule of Law Conflicts of Poland and Hungary within the EU». Journal of Comparative Politics, vol 11, n. ${ }^{\circ} 2,2018$ pp. 30 y ss, en especial, 32 a 38. En castellano véanse los trabajos de LóPEZ AguiLAR, J.F. «El caso de Polonia en la UE: retrocesos democráticos y del Estado de Derecho y "dilema de Copenhague"», TRC, n.38, 2016 pp. 101 y ss y «De nuevo (y todavía) Polonia: Rule of Law y art. 7 TUE en el Parlamento Europeo y el Tribunal de Justicia», TRC, n. ${ }^{\circ} 44,2019$, pp. 137 y ss.

37 Es indicativo del clima político en el que se aplicaron los criterios de Copenhague y del optimismo existente al respecto que en el caso de los dos Estados que no cumplieron los estándares mínimos (Rumanía y Bulgaria) se creó un mecanismo específico de supervisión de su cumplimiento, pero no se impidió su ingreso en la UE. Dichos mecanismos siguen, 14 años después, vigentes y la Comisión continúa informando de los problemas aún existentes al respecto.

38 Posiblemente no era solo un problema de malas herramientas jurídicas pues también existía un problema político que el propio AGH (ibídem, p. 32 y ss) resume en la paradoja Juncker para describir la policrisis que hubo de afrontar el presidente de la Comisión durante su mandato (crack financiero, crisis de los refugiados, Brexit y regresiones del Estado de Derecho) que hacía imposible actuar con eficacia contra los acontecimientos en Hungría, Polonia y otros Estados miembros de la UE. 
reclamaciones realizadas por los propios jueces. La secuencia temporal de los leading cases es ciertamente muy clara: Volkov c Ucrania (2013); Baka c Hungría (2014 Sala y 2016 Gran Sala), Nunes de Carvalho e Sa c. Portugal (2016 Sala y 2018 Gran Sala).

La evolución en la UE también va a ser muy clara. Ya en 2012 en su discurso anual sobre el Estado de la Unión, el presidente Barroso puso de relieve la necesidad de crear mecanismos intermedios entre la «mano suave» de la persuasión política y la «mano dura» del artículo 7 del TUE. Sin embargo, finalmente, la Comisión acabó poniendo en marcha la mano dura que para el presidente Barroso debía evitarse. Veamos los instrumentos en orden cronológico y la influencia del soft Law examinado ${ }^{39}$.

\section{b) El EU Justice Scoreboard} board.

Una primera y muy débil aproximación va a ser la creación del Justice Socre-

En efecto, desde 2013 la Comisión Europea elabora el Cuadro de Indicadores de la Justicia en la UE ${ }^{40}$ (EU Justice Scoreboard). Dicho documento es, según se sostiene en su última edición, una herramienta de información comparativa que confiere datos objetivos, fiables y comparables sobre la calidad, independencia y eficiencia de los sistemas judiciales. Se trata por tanto de ofrecer una visión general del funcionamiento del poder judicial de los Estados miembros que pueda ayudar a la UE y a los propios Estados para mejorar su funcionamiento.

Buena parte de los datos los suministra a su vez un órgano consultivo del CoE: la Comisión para la Eficacia de la Justicia del Consejo de Europa (CEPEJ) con la que la Comisión ha suscrito un contrato para un estudio anual específico y que comienza en 2010. La CEPEJ es un órgano consultivo creado mediante la Resolución (2002)12 del Comité de ministros de 18 de septiembre de 2002. Se pretendía crear un órgano cuya finalidad fuera doble: mejorar la eficiencia y el funcionamiento de los poderes judiciales de los Estados miembros y hacer posible una mejor implementación de los instrumentos del CoE relativos a la eficiencia y equidad de la justicia. La Comisión tiene como objetivo fomentar la

39 Como ya hemos apuntado no se examinará en el texto la reacción jurisprudencial que desde 2018 está siendo extraordinariamente importante puesto que la influencia de los instrumentos de soft law del CoE permanece oculta. Debe destacarse, sin embargo, que en menos de dos años ha cambiado radicalmente su modo de afrontar la cuestión de la independencia judicial. Pasando desde una aproximación puramente funcional o utilitarista (vinculada al reconocimiento del máximo de órganos legitimados para plantear cuestiones prejudiciales) a un concepto constitucional. La secuencia cronológica de las sentencias básicas que abordan cuestiones esenciales de la independencia judicial es vertiginosa desde 2018 a 2020.

40 Pueden consultarse todos estos cuadros en https://ec.europa.eu/info/policies/justice-and-fundamental-rights/upholding-rule-law/eu-justice-scoreboard_en visitado por última vez 25/01/2021. 
cooperación entre los Estados y entre las distintas organizaciones internacionales con los fines concretos de analizar el funcionamiento de los poderes judiciales, orientar las políticas públicas en materia de justicia, promover la calidad de la justicia; facilitar la implementación de los estándares europeos en el campo de la justicia y apoyar a los Estados en la reforma de la organización de sus tribunales.

El CEPEJ, por tanto es un órgano especializado en el diagnóstico del correcto funcionamiento de los poderes judiciales. En ese marco ha creado los mecanismos necesarios para realizar la evaluación del funcionamiento del poder judicial. No se trata de un órgano específicamente dirigido a la garantía de la independencia judicial. Sin embargo, la labor que desde 2002 ha desarrollado el CEPEJ, a iniciativa propia o de otros órganos, ha permitido generar una serie de instrumentos esenciales en esa función de evaluación. Herramientas que han incorporado buena parte de los documentos jurídicos componentes de la definición de la independencia judicial en el soft Law.

En la elaboración del Justice Scoreboard intervienen otros organismos entre los que destacan la Red Europea de Consejos del Poder Judicial (RECPJ), la red presidentes de los Tribunales Supremos de la Unión Europea o la Red Europea de Formación Judicial. De este modo la CEPEJ no solo suministra los datos sino también los indicadores, la metodología y la evaluación que va a ser compilada en el Scoreboard ${ }^{41}$.

Esta información aportada por el Scoreboard permite evaluar la independencia y la eficiencia de los sistemas judiciales. Igualmente genera un debate en su elaboración entre las autoridades nacionales y las europeas. En fin, puede provocar que la Comisión adopte recomendaciones específicas por país sobre la mejora de los sistemas judiciales.

El Scoreboard provee de una visión general de los elementos básicos que permiten valorar la evolución del Estado de Derecho y de la independencia judicial en los Estados miembros. Es un mecanismo básico de información que pretende prevenir cualquier forma de control político de las decisiones judiciales. Por todo ello se convierte en un elemento esencial de la nueva estrategia aprobada en 2019 para la defensa del Rule of Law en la UE. Instrumento informativo que incorpora buena parte de las conclusiones y elementos que constituyen el acervo del soft Law del CoE sobre independencia judicial.

Este instrumento de carácter meramente informativo no ha sido suficiente para que la UE afrontara las derivas de regresión en el Estado de Derecho en algunos de los Estados miembros provocó que la Comisión adoptara una nueva estrategia complementaria.

41 Sobre la conexión entre Comisión Europea y CEPEJ para la elaboración del EU Justice scoreboard véase BACHMAIER Winter, L. «Judicial independence in the Member States of the Council of Europe and the EU: evaluation and action», ERA Forum, 20; 2019, pp. 113 y ss y para la descripción de las dificultades técnicas para medir la eficacia de los poderes judiciales, pp. 117 y ss. 
c) El primer plan de acción de la Comisión (2014): el marco para el fortalecimiento del Rule of Law en la UE

El plan de acción de la Comisión es aprobado el 11 de marzo de 2014 en forma de Comunicación al Parlamento y al Consejo bajo el título «Un nuevo marco de la UE para reforzar el Estado de Derecho» ${ }^{42}$.

En dicho texto la Comisión se apoya en los documentos del Consejo de Europa ya expuestos para definir los elementos básicos del Estado de Derecho y destaca, como punto de partida, su carácter basilar en el funcionamiento de la UE.

Igualmente subraya que, si los mecanismos nacionales para la protección del Estado de Derecho dejan de ser eficaces, se produce una amenaza sistémica para el propio Estado de Derecho y con ello para la UE en cuanto espacio de libertad, seguridad y justicia sin fronteras exteriores. En tal contexto, la UE ha de actuar para proteger el Estado de Derecho como valor común de la UE. Sin embargo, los instrumentos existentes en la UE no parece que sean totalmente eficaces para afrontar este tipo de situaciones. En primer término, la iniciativa para la incoación de procedimientos de incumplimiento sobre la base del art. 258 TFUE es un instrumento relevante. Pero requiere que las situaciones lesivas del Estado de Derecho en los Estados supongan, simultáneamente, una infracción de una disposición específica del Derecho de la UE. En los casos que quedan fuera del ámbito de aplicación del Derecho de la UE el único mecanismo de prevención y de sanción es el establecido en el art. 7 TUE cuyas dificultades de aplicación son más que evidentes.

A la vista de las situaciones de crisis del Estado de Derecho experimentadas por algunos de los miembros de la UE y la insuficiencia de ambos instrumentos se requiere un nuevo Marco de la UE para reforzar el Estado de Derecho como complemento «de todos los mecanismos ya existentes al nivel del Consejo de Europa para proteger el Estado de Derecho».

El objetivo del Marco era que la Comisión acordara con el Estado afectado una solución para evitar la aparición de una amenaza sistémica al Estado de Derecho que pudiera abocar a la aplicación del art. 7 TUE.

El Marco entiende por crisis sistémicas aquellas que afectan a alguno de los seis principios básicos del Estado de Derecho tal y como han sido definidos en los instrumentos del $\mathrm{CoE}$ (son explícitas las referencias tanto a los trabajos de la Comisión de Venecia, como a los seis principios básicos del Estado de Derecho formulados en su informe sobre Rule of Law y en la Checklist examinados más arriba) y en ningún caso impedirá que la Comisión pueda utilizar otros mecanismos (como las acciones por incumplimiento del art 258 TFUE).

El Marco se articulaba como un diálogo entre Comisión y Estado en tres fases: evaluación, recomendación y seguimiento. Para realizar estas labores, la 
Comunicación reconocía la práctica habitual de solicitar asesoramiento y asistencia a las redes judiciales, así como a los órganos del CoE y de la Comisión de Venecia.

El marco, señalan Von Bogdandy y otros ${ }^{43}$, presentaba tres rasgos básicos. En primer lugar, respecto su ámbito de aplicación aparentemente se refiere solo a la garantía del Estado de Derecho y no a todos los valores del art. 2. Sin embargo, la Comisión utiliza un concepto amplio de éste (en la estela del informe de la Comisión de Venecia sobre el tema y su checklist) que en gran medida incluye el respeto a la democracia y a los derechos humanos. En segundo lugar, se asume la presunción de que en los Estados se respeta las reglas básicas del Rule of Law y por ello no se refiere a violaciones concretas de éste, sino a situaciones extremas de riesgo para el Estado de Derecho. En tercer lugar, el papel esencial es de la Comisión, no del Consejo; lo que llevó a los servicios jurídicos de este a dudar de su conformidad con el principio de atribución de competencias porque las acciones de la UE para proteger los valores del art. 2 son, a su juicio, solo y exclusivamente las previstas en el art. 7 TUE. Para la Comisión, sin embargo, no se trataba de ejercicio de competencias sino de un conjunto de normas para clarificar el modo de actuar de la comisión antes de poner en marcha los mecanismos del art. 7 TUE.

Lo cierto es que el marco presentaba algunas carencias de diseño importantes $^{44}$. No preveía ninguna sanción, sino que más bien se trataba de una especie de diálogo soft ${ }^{45}$ que no llevaba aparejada ninguna consecuencia excepto la de poner en marcha el mecanismo del art. 7.1

Sea como fuere las críticas relativas a la posible poca eficacia del marco se mostraron fundadas tras el fracaso de esta estrategia respecto a la regresión en el Estado de Derecho producida en Polonia ${ }^{46}$ y que acabó provocando la puesta en marcha del procedimiento preventivo del art. 7.1 TUE, las acciones por incumplimiento ante la Comisión, y las numerosas condenas del TJ respecto a la situación de la independencia judicial en Polonia.

\section{d) El recurso al artículo 7.1 TUE}

Como se acaba de señalar, el Plan de Acción recién descrito no pudo evitar que finalmente se pusiera en marcha el mecanismo mecanismo preventivo

43 Von Bogdandy, A. \& Carlino Antpöhler, C. \& IoAnnidis, M. «Protecting EU Values. Reverse Solange and the Rule of Law Framework», MPIL Research Paper Series, 2016-4, pp. 11-14.

44 Halmai, G. How the EU Can and Should Cope with Illiberal States, Quaderni Costitutzionali, XXXVIII, 2, 2018, pp. 326-327.

45 Sмiтh, M. (2019): «Staring into the Abyss: A crisis of rule of law in the EU», European Law Journal, 25, 2019, p. 571.

46 Sobre el modo en que se realizaron las fases del Marco en el caso polaco véanse por todos; J. MARTíN Y Pérez De Nanclares, «La Unión Europea como comunidad de valores: a vueltas con crisis de la Democracia y del Estado de Derecho», TRC, 43, 2019, pp. 152-154; Halmai, G. ibidem, p. 313, p. 335 y J.F. López Aguilar, «El caso de Polonia en la UE: retrocesos democráticos y del Estado de Derecho y "dilema de Copenhague"», citado, pp. 137 y ss. 
previsto en el artículo 7.1 TUE, primero por la Comisión respecto a Polonia y después por el Parlamento respecto a Hungría.

En el caso polaco fue la Comisión la que elevó una propuesta motivada y activó el mecanismo el 20 de diciembre de $2017^{47}$.

La influencia del soft law examinado en la propuesta es extraordinariamente clara desde el segundo párrafo de la misma en la que se hace una referencia expresa al mismo y en particular a la experiencia de la Comisión de Venecia que aparece citada en más de 40 ocasiones a lo largo del texto. Citas que se refieren a la aplicación de sus estándares con carácter general (por ejemplo, par. 57.5), a la necesidad de que Polonia colabore con ella (así, par. 13) o los continuos llamamientos durante las negociaciones reguladas por el Plan de Acción a que respetara y aplicara los dictámenes emitidos por la Comisión (así, par 20), denunciado incluso las actitudes desleales del Gobierno polaco respecto a su actuación (pars. 13 ó 32). Sin embargo, la clave posiblemente está en las referencias a los sucesivos dictámenes emitidos en relación con los ataques a la independencia judicial (así, por ejemplo, pars $18,32,88$ ) de modo que en cada una de las normas internas consideradas violación de dicha independencia, la Comisión, suma a sus argumentos los expresados por el citado órgano del CoE: pars 94 y 95, respecto a la composición del Tribunal Constitucional; par. 98 respecto a la (no) publicación de sus sentencias; pars. 116, 120, 121, 126,130, 132, 135, 136 respecto a la ley del Tribunal Supremo; par. 144 respecto a la ley del Consejo Judicial; pars. 148, 158, respecto a la ley de los Tribunales Ordinarios;. Igualmente destacable que también aparezcan las menciones en la constatación final de existencia de un riesgo grave del Estado de Derecho (pars. 177, 178, 179). Incluso en la parte dispositiva de la propuesta de Decisión realizada al Consejo entre las medidas que éste ha de recomendar incluye: «velar porque cualquier reforma del sistema judicial se elabore en estrecha cooperación con el poder judicial y todas las partes interesadas incluida la Comisión de Venecia» ${ }^{48}$.

Las referencias al soft law, y en particular a la labor de la Comisión de Venecia van a ser también muy relevantes en la Propuesta de Decisión al Consejo aprobada por el Parlamento Europeo para la defensa del Estado de Derecho en Hungría el 12 de septiembre de $2018^{49}$. En este sentido en la motivación de su

47 Propuesta de Decisión del Consejo relativa a la constatación de un riesgo claro de violación grave del Estado de Derecho por parte de la República de Polonia, COM(2017)835 final, 20/12/2017.

48 Debe notarse que, según las noticias periodísticas, esta misma recomendación se realizó de manera informal por parte de la Comisión al Gobierno español con motivo de la proposición de ley que pretendía la modificación del sistema elección de los vocales del CGPJ: Proposición de L.O. por la que se modifica la L.O.P.J. para la reforma del procedimiento de elección de los Vocales del C.G.P.J. correspondientes al turno judicial y para el establecimiento del régimen jurídico aplicable al C.G.P.J. en funciones, BOCG. CD N. ${ }^{\circ}$ B-120-1 de 23/10/2020.

49 Propuesta de Decisión del Consejo, relativa a la constatación, de conformidad con el art. 7, apartado 1, del Tratado de la Unión Europea de la existencia de un riesgo claro de violación grave por parte de Hungría de los valores que fundamentan la Unión, 12/09/2018, P8_TA(2018)0340. 
propuesta hace clara referencia a los sucesivos informes de la Comisión de Venecia en relación con Hungría en lo referente al funcionamiento del sistema constitucional (pars 7, 8, 10), la independencia judicial y los derechos de los jueces (pars. 12 y 19), libertad de expresión (pars 27, 28 y 29), libertad de cátedra (pars. 33 y 34), libertad religiosa (par. 37) y libertad de asociación (par. 41, 42, $44,45)$. Con tales referencias el Parlamento, en el anexo a la Resolución, trata de acreditar la situación de riesgo grave para el Estado de Derecho también en Hungría.

e) El segundo plan de acción de la Comisión (2019)

La experiencia obtenida y los resultados (y fracasos) alcanzados en la aplicación del Plan de Acción anterior y las concretas relaciones establecidas con distintos órganos en los últimos años y descritas más arriba han servido para diseñar un plan de acción futuro incorporándose a la Comunicación de la Comisión Europea «Refuerzo del Estado de Derecho en la Unión», aprobada el 17 de julio de $2019^{50}$. El punto de partida es, como señaló Crabit en la presentación del texto final, que el tradicional sobrentendido de que los Estados miembros de la UE respetaban los elementos esenciales del Estado de Derecho, ha desaparecido ${ }^{51}$.

La actuación de la Comisión en la defensa del Estado de Derecho ahora se sitúa en tres ejes fundamentales: promoción, prevención y reacción.

Respecto a la promoción, la Comisión considera que la existencia de una cultura política y jurídica fuerte de apoyo al Rule of Law en cada Estado constituye la mejor garantía de la su vigencia. Para ello se compromete a atribuir fondos para la promoción del Estado de Derecho en la sociedad civil y en la academia; fortalecer la cooperación con el CoE; incrementar la cooperación con otras organizaciones internacionales, aumentar la cooperación con las redes judiciales y desarrollar estrategias de comunicación.

En lo atinente a la prevención, la Comisión adopta una estrategia de cooperación y apoyo para fortalecer el Estado de Derecho a nivel nacional. En tal sentido destaca que los Tribunales Constitucionales, los Defensores del Pueblo y los jueces son la primera línea de defensa ante los ataques al Rule of Law. La Comisión se compromete a apoyar la cooperación para evitar llegar a la fase de sanción o respuesta. Por ello ha creado mecanismos de control y propone la puesta en marcha de otros para asegurarse de que cualquier ataque o crisis de Estado de Derecho en un Estado miembro pueda ser detectada rápidamente por la Comisión y, así, actuar tempestivamente para atajar la amenaza.

$50 \operatorname{COM}(2019) 343$ final. 17/07/2019.

51 E. Crabit, «Developing the EU Policy on Rule of Law», Craig, P. y otros, Rule of Law in Europe: Perspective from practitioners and academics. European Judicial Training Network, Bruselas 2019, p. 87. 
En tal sentido propone la creación de un Ciclo de Revisión del Estado de Derecho. Este ciclo cubrirá todos los componentes del Estado de Derecho con especial atención a la independencia judicial (ataques a la independencia, a jueces individuales o al poder judicial en su conjunto), la lucha contra la corrupción y la ejecución correcta del Derecho de la UE ${ }^{52}$.

Para ello se usarán como fuentes de información tres tipos de mecanismos. En primer lugar, los instrumentos diseñados por la Agencia de Derechos Fundamentales de la UE (FRA) y en participar el Sistema de información de derechos fundamentales de la UE (EFRIS) y los informes sobre los países. En segundo lugar, los propios Estados y otros socios. En concreto de los Estados se recabará toda la información disponible creándose una red de puntos de contacto. Del resto de socios se usarán otros mecanismos de información a través de la relación con los órganos del CoE, OSCE, OCDE y de las redes judiciales.

El ciclo incluirá como resultados relevantes la aprobación de dos informes. Por un lado, la Comisión se compromete a la aprobación de un nuevo instrumento como es el Informe anual sobre Estado de Derecho resumiendo la situación en los distintos Estados miembros que incluya una síntesis de los desarrollos más significativos en todos los Estados y en la UE. Por el otro, también se compromete a potenciar el ya existente $E U$ Justice Scoreboard para ofrecer los datos comparativos sobre independencia, calidad y eficacia de los sistemas de justicia nacionales.

Finalmente, la reacción ha de producirse cuando los mecanismos de defensa del Estado de Derecho fallen. Para la Comisión, cuando un Estado no es capaz de resolver por sí mismo las amenazas al Estado de Derecho, es responsabilidad común de la UE y del resto de Estados miembros tomar las decisiones necesarias para remediar la situación. La Comisión por tanto llevará los casos de violación al Rule of Law ante el Tribunal de Justicia cuando el Estado no luche contra tales violaciones. Además, para evitar al máximo el daño a un valor tan esencial, solicitará todas las medidas cautelares oportunas y el uso de procedimientos acelerados. La rapidez es, para la Comisión, clave para poder revertir los efectos negativos de la actuación. Un segundo mecanismo será sin duda el previsto en el art. 7 TUE. Pero propone un marco coherente de actuación en el que ante la existencia de deficiencias estructurales se puedan producir la suspensión de mecanismos vinculados al Espacio de Libertad Seguridad y Justicia o recortar la financiación de ciertos programas europeos.

En el marco de este Plan de Acción la Comisión aprobó el 30 de septiembre de 2020 el primer informe sobre la vigencia del Estado de Derecho en los países miembros de la $\mathrm{UE}^{53}$. Dicho texto está compuesto por un informe global

52 La idea de un ciclo de revisión del Estado de Derecho en todos los Estados había sido apuntada en términos muy similares, apoyándose en la experiencia del CoE y de la Comisión de Venecia por HaLmaI, G. citado: p. 329.

53 Informe sobre el Estado de Derecho en 2020. Situación del Estado de Derecho en la UE, $\operatorname{COM}(2020) 580$ final, 30 septiembre de 2020. 
y otro individualizado por cada uno de los Estados. La importancia de los materiales suministrados por el $\mathrm{CoE}$, tanto de sus órganos políticos como consultivos, aparece con toda claridad tanto en la metodología adoptada ${ }^{54}$, como en el propio contenido de los informes. Respecto a la metodología resulta interesante destacar que ha incluido la consulta al $\mathrm{CoE}$ resuelta con una información individualizada por Estado del Directorado General de Derechos Humanos y Estado de Derecho en el que se recogen todas las valoraciones realizadas por los distintos órganos del $\mathrm{CoE}$ en relación con la materia y muy singularmente con la garantía de la independencia judicial ${ }^{55}$. Obviamente los informes de la Comisión de Venecia ocupan un lugar destacado en tal documentación.

Pero más allá de esta labor consultiva, el propio informe recoge con carácter general que las «recomendaciones y opiniones del Consejo de Europa proveen un marco útil de referencia para los estándares y mejores prácticas» y apunta la necesidad de cooperar en la materia con la Comisión de Venecia. Sea como fuere, la estructura y contenidos del soft law de Estrasburgo puede seguirse con claridad en el capítulo referido a los sistemas de justicia de los Estados miembros de la UE, en el informe global y las referencias a los instrumentos del CoE en los informes nacionales es constante ${ }^{56}$ mostrando con claridad meridiana que la influencia del soft law discutido y elaborado en el seno de los órganos del CoE ejerce y, presumiblemente, ejercerá una significativa influencia en el futuro control del respeto al Estado de Derecho y a la independencia judicial en los Estados miembros de la UE.

TITLE: The influence of non-biding Council of Europe documents on judicial independence at the $E C t H R$ and within the $E U$

ABSTRACT: This essay focuses on the documents on judicial independence drafted by Council of Europe bodies. It takes into account its diverse approaches before and after the rule of Law backsliding in some European States since 2010. The basic standards elaborated are summarized. Its influence is addressed both at the Council of Europe and at the European Union. In the first sense it examines the influence of this soft law in the European Court of Human Rights case law. Secondly it focuses in the way it has conditioned the European Commission task of monitoring the effectiveness of rule of law in EU member states. This influence began when they were used to evaluate the candidatures of Eastern European countries to join the EU at the end of the last century but it has kept inspiring the Commision's activities until the Report on Rule of Law issued in October 2010.

54 Dicha metodología fue adoptada el 20/09/2020 y puede consultarse en https://ec.europa.eu/info/ files/2020-rule-law-report-methodology_es.

55 Pueden consultarse todos estos informes en https:/ec.europa.eu/info/publications/2020-rule-lawreport-targeted-stakeholder-consultation_es

56 Pueden verse, a modo de ejemplo, las referencias del informe sobre Hungría (SWD(2020)316 final) en la lista de fuentes utilizadas (pp. 23 y ss.) en las que 24 de las 66 aportaciones proceden del CoE y de ellas, 11 son informes de la Comisión de Venecia. Todos los informes nacionales pueden consultarse en https:// ec.europa.eu/info/publications/2020-rule-law-report-communication-and-country-chapters_es 
RESUMEN: el artículo examina los documentos elaborados sobre independencia judicial por distintos órganos del Consejo de Europa. Tiene en cuenta la diferente aproximación en los mismos antes y después de la crisis del Estado de Derecho en algunos de los Estados europeos a partir de 2010. Tras resumir los estándares básicos elaborados en tales textos, se estudia su influencia en el Consejo de Europa y en la UE. En el primer sentido se examina su presencia en la jurisprudencia del TEDH. Respecto a la UE se examina el modo en que ha condicionado la labor de la Comisión en la supervisión del respeto al Estado de Derecho por los Estados miembros desde que comenzara a usarlos para evaluar las candidaturas de los países del Este a ingresar en la UE a finales del pasado siglo, hasta su incorporación al Informe sobre el Estado de Derecho en la UE aprobado en octubre de 2020.

KEY WORDS: Rule of Law backsliding, Judicial Independence, soft law, Council of Europe, European Union.

Palabras Clave: crisis del Estado de Derecho, Independencia Judicial, soft law, Consejo de Europa, Unión Europea.

FECHA DE RECEPCIÓN: 26.10.2020

FECHA DE ACEPTACIÓN: 26.01.2021 